\title{
De cómo el Cid se ganó el respeto de don Remont*
}

\section{How The Cid Earned don Remont's Respect}

Alfonso Boix Jovaní

Investigador independiente

alba_qu_bra@yahoo.com

Para Nora Gómez
y Víctor Infantes,
in memoriam

Este artículo plantea una nueva interpretación del episodio de don Remont en el Cantar de Mio Cid tras demostrar, a partir de una exhaustiva revisión, que la tradicional lectura humorística del mismo se ha basado en el muy cuestionable análisis que desarrolló Montgomery. Sin la supuesta comicidad, el episodio resulta coherente por completo con el resto del poema, mientras que la lectura humorística dejaba a la aventura sin sentido con respecto al conjunto del texto épico.

Palabras Clave: Cantar de Mio Cid, Conde de Barcelona, humor, nobleza, respeto

This article offers a new interpretation of the episode of don Remont in the Cantar de Mio Cid after showing, by means of a thorough revision, that its traditional humorous reading was based upon a very questionable analysis developed by Montgomery. By avoiding that supposed comicalness, the episode becomes completely coherent with the rest of the poem, whereas the humorous reading left this adventure as a meaningless chapter within the whole epic text.

KeYwords: Cantar de Mio Cid, Count of Barcelona, humour, nobility, respect

FECHA DE RECEPCIÓN: 23/10/2016

FECHA DE ACEPTACIÓN: 02/12/2016

* El presente trabajo se inscribe en las actividades del Proyecto del Plan Nacional de I+D+i del Ministerio de Economía y Competitividad FFI2015-64050: Magia, Épica e Historiografía Hispánicas: Relaciones Literarias y Nomológicas, dirigido por el doctor Alberto Montaner Frutos. 


\section{INTRODUCCIÓN}

El episodio del conde de Barcelona constituye uno de los pasajes más célebres del Cantar de Mio Cid (CMC, en adelante) y, por ello, ha sido importante objeto de estudio. Según relata el poema castellano, el Cid entra en tierras del conde, saqueándolas (v. 958), a lo que reacciona don Remont, ${ }^{1}$ quien, altanero, desprecia al Campeador y le presenta batalla.

El conde es muy follón e dixo una vanidat

-Grandes tuertos me tiene mio Cid el de Bivar,

dentro en mi cort tuerto me tovo grand,

firióm’ el sobrino e no·n lo enmendó más;

agora córrem' las tierras que en mi enpara están.

Non lo desafié ni.l' torné amistad, mas, cuando él me lo busca, írgelo he yo demandar.-

$(\text { vv. } 960-966)^{2}$

Don Remont marcha con un poderoso contingente de moros y cristianos en busca del Campeador (vv. 967-999), quien, al saber las intenciones del conde, trata de disuadirle:

—Digades al conde non lo tenga a mal, de lo so non lievo nada, déxem' ir en paz.-

Respuso el conde: _ — ¿Esto non será verdad!

¡Lo de antes e de agora todo.m’ lo pechará, sabrá el salido a quién vino desondrar!-

Tornós' el mandadero cuanto pudo más; essora lo coñosce mio Cid el de Bivar que a menos de batalla no.s' pueden den quitar:

${ }^{1}$ El Cid se enfrentó históricamente a su hermano Berenguer Ramón II el Fratricida en la batalla de Tévar (1090). De hecho, Ramón Berenguer II Cabeza de Estopa llevaba ya varios años muerto cuando se produjo la batalla. Sin embargo, el CMC nombra al rival del Campeador como "don Remont", lo cual se ha entendido como una confusión de nombres o a que, en realidad, el poeta creyó que el Cid combatió a Ramón Berenguer II. Para Montaner, este equívoco "puede deberse a que, entre 1076 y 1082, gobernaron conjuntamente Ramón Berenguer II y su hermano, y posterior asesino, Berenguer Ramón II" (Cantar, 60 [1993: 158; 2007: 60]). El presente estudio presentará una alternativa, aportando pruebas de que esa aparente confusión onomástica respondió a un propósito concreto y coherente con el poema.

${ }^{2}$ Cito el $C M C$ en este artículo siempre a partir de la edición de Montaner. 
Navarrete ("Ideología", 238), haciendo hincapié en la brevedad de la narración dedicada a la contienda, resalta cómo "el juglar, que dedica más de trescientos versos del cantar a relatar el episodio, probablemente ficticio, de la toma del castillo de Alcocer despacha la batalla de Tévar en once escuetos versos", a saber:

Todos son adobados cuando mio Cid esto ovo fablado,
las armas avién presas e sedién sobre los caballos;
vieron la cuesta yuso la fuerça de los francos.
Al fondón de la cuesta, cerca es del llano,
mandólos ferir mio Cid, el que en buen hora nasco;
esto fazen los sos de voluntad e de grado,
los pendones e las lanças tan bien las van enpleando,
a los unos firiendo e a los otros derrocando.
Vencido á esta batalla el que en buen hora nasco,
al conde don Remont a presón le á tomado.
Ý gañó a Colada, que más vale de mill marcos de plata,

Sin embargo, la desproporción entre el número de versos y la relevancia de un episodio no es algo exclusivo de la batalla de Tévar, pues también se produce en la toma de Valencia (vv. 1202-1212) donde el poema prefiere no estancarse en el relato de un largo asedio sin maniobras destacables, ${ }^{3}$ frente a lo que sucede en Castejón y Alcocer, conquistadas mediante hábiles estratagemas, de ahí que reciban un tratamiento más detallado que Valencia. Esto mismo puede aplicarse a la batalla de Tévar, pues, como bien señaló West ("A Proposed Literary Context", 1), "the significance of the Tévar episode [... lies in the preliminaries to the battle and in its aftermath, rather than in the battle itself. This conclusión emerges from even the most cursory reading, as mere eleven lines (1000-10) are devoted to the hostilities out of a total of one

\footnotetext{
${ }^{3}$ Para Montaner, "más que las habilidades guerreras del Campeador, interesa resaltar su capacidad de convocatoria (vv. 1197-1200 y 1267), así como la importancia del botín conseguido (vv. 1210-1220), marcada por la reiteración de la fórmula ponderativa '¿quién vos lo podrié contar?' (v. 1214), '¿quién los podrié contar?’ (v. 1218). En todo caso, y desde la perspectiva militar, el segundo hemistiquio del verso 1204, 'que non ý avía art', establece la diferencia con la toma de las otras dos plazas aludidas [Castejón y Alcocer], que se realiza, justamente, gracias a estratagemas, por lo reducido del ejército cidiano" (Cantar, 806-807 [1993: 503; 2007: 461]).
}

Medievalia 49, 2017, pp. 21-61 
hundred and twenty-eight (957-1084)". ${ }^{4}$ De entre todos ellos, el apartado que nos interesa comprende los vv. 1017-1082, pasaje muy conocido y cuyos versos serán citados a lo largo del presente estudio conforme el análisis de los mismos así lo exija.

Ya Dámaso Alonso ("Estilo y creación”, 359) observó diversos aspectos del pasaje que pueden entenderse como humorísticos. Con respecto al conde y su caracterización en el poema,

Notemos con cuán escasos recursos estilísticos está conseguido el intento, cuán delgada es la gracia. Los elementos son pocos, pero suficientes, pero irremplazables. No hay uno que no venga a fijar un punto del perfil del conde. A este fin apunta la cualidad de follonía que primero se le atribuye; a esto —burguesía, vida fácil y cómoda, escasez de heroísmo-, las alusiones a los cortesanos vestidos, a las sillas más propias de gala y torneo que de lides; a esto también, la petición de aguamanos. A esto, la melancolía que se apodera del conde en la prisión; a esto, su poca firmeza de carácter, su debilidad, que le hace faltar en seguida a la palabra dada de no probar bocado; a esto, su desconfianza, tan poco heroica. Unas cuantas indicaciones, sabiamente espaciadas, dejada caer con un matiz estilístico ingenuo, en donde parece casi no apuntar la ironía, nos han dejado un retrato complejo, perfecto, del tipo del vanidoso y de poco ánimo.

Queda así resumida la lectura habitual del episodio: un retrato humorístico, poco heroico, del conde don Remont. Sin embargo, se observan ciertos elementos subjetivos, como la supuesta "melancolía que se apodera del conde en la prisión” sobre la cual nada indica el CMC. Más allá de este detalle, la interpretación humorística del episodio ha sido una constante desde hace años, pues no hay artículo sobre el Cid y don Remont que no se refiera en algún momento a dicha comicidad, o a la generalmente aceptada humillación por parte del Cid hacia el catalán, siguiendo las tesis planteadas por Montgomery ("The Cid and the Count"), ${ }^{5}$ autor de "the first detailed study of the

\footnotetext{
${ }^{4}$ Respondiendo así a Burgoyne ("Si bien non comedes", 40), para quien "Most critics have called attention to the battle scene (vv. 985-1011) for its lack of descriptive detail, and the impression it creates of a disconnection between the narrated and the narration, or story time and discourse time, especially when this confrontation is compared with the rhythm of other combat narratives in the poem".

5 Aunque Dámaso Alonso ("Estilo y creación”, 358-359) vio rasgos cómicos en don Remont, no sería hasta el conocido estudio de Montgomery ("The Cid and the Count") que se plantearía la lectura basada en una supuesta humillación.
} 
episode” (West, “A Proposed Literary Context”, 2) y que gozó por ello de gran éxito, pasando a ser referencia obligada de todos los trabajos dedicados a esta aventura que, si bien han ofrecido magníficos hallazgos, también han incurrido en una lectura contradictoria con el conjunto del poema, además de ir incluso contra la propia figura del Campeador; una interpretación que requiere de malabares para explicar por qué el Cid obsequia al conde con ricas monturas antes de partir, o por qué el Campeador califica de "buen señor" al barcelonés en las cortes de Toledo (v. 3194). Lo que propongo, por tanto, es una revisión de la escena prescindiendo de tal humor, así como de la consabida humillación sufrida por don Remont, lo cual puede dar más sentido a la función de este episodio en el poema.

\section{¿POR QUÉ EL CONDE NO QUIERE COMER?}

Puesto que el Cid trata de convencer a don Remont de que acepte la comida que le ofrece, será necesario comprender qué motiva su ayuno. Un buen número de autores han visto en ello una huelga de hambre, siguiendo la idea planteada por Dámaso Alonso ("Estilo y creación”, 358): "El conde intenta la huelga de hambre $[. .$.$] . Pero, cuando a los tres días le oye al Cid que si come$ le pondrá en libertad, entre aquella promesa y el buen apetito medieval y templado por tres días de abstención, cambia de parecer y olvida su voto”. Quienes comparten esta lectura evidencian los puntos débiles de dicha huelga: o no especifican cuál es el motivo u objeto de la misma, ${ }^{6}$ o creen que su propósito es el de obtener la libertad, como Garci-Gómez (Estudios, 124-127, 131),

${ }^{6}$ Para Oleza ("Análisis estructural”, 198) "el conde de Barcelona, que declara una especie de pasiva huelga de hambre"; reitera la idea poco después, al afirmar que "[el Cid va a] poner en contradicción la dignidad personal del Conde y su deseo de libertad, va a hacernos entrar en conflicto, y vamos a ver al Conde agachar las orejas y salir con el rabo entre las piernas, confiriendo al episodio su característico humor" ("Análisis estructural”, 203); según Beltrán (“Conflictos interiores”, 241), "El catalán parece estar diciendo que prefiere morir a tener que pagar con lo cual no hay razón para que el Cid lo mantenga prisionero y sí, e importante, para dejarlo ir ya que la muerte del conde como prisionero suyo hubiera supuesto gravísimos inconvenientes para Rodrigo"; para López Estrada (Panorama crítico, 235), "el juego oral se establece sobre todo a través de los comentarios del Cid que suscitarían la risa de los oyentes: [y cita los vv. 1054-1055] [.] El amable interés del Cid por la buena comida del Conde es el contrapunto de la huelga de hambre que éste pretendía llevar a cabo y que no pudo sostener"; para Giles ("Del día que fue conde", 122), el episodio nos muestra "Remont's aborted hunger strike"; finalmente, según Burgoyne ("Si bien non comedes”, 31), "the Cid coerces his prisoner, Ramón Berenguer, the Count of Barcelona, to give up his airs and end his hunger strike”.

Medievalia 49, 2017, pp. 21-61 
para quien "Nos encontramos, evidentemente, con un caso del uso del ayuno como medio de coerción para obtener la libertad; fue, además, un medio muy eficaz" (Estudios, 125), alzando al conde con el triunfo final al imponerse al Cid, quien, de ser así, acabaría humillado al doblegarse a las pretensiones de su prisionero, ${ }^{7}$ como agudamente observó West ("A Proposed Literary Context", 2) al advertir que "it is, therefore, the Cid who is obliged to change his stance, rather than the Count".

Para Montgomery ("The Cid and the Count", 5), Vidal Tibbits ("Cid, hombre heroico", 272), ${ }^{8}$ Smith ("Tone of Voice”, 10) ${ }^{9}$ y Such y Hodgkinson (Poem of my Cid, 102), ${ }^{10}$ el alimento que se ofrece a don Remont constituye un banquete para celebrar la victoria del Cid y, por tanto, la derrota del catalán. ${ }^{11}$ La primera referencia a esta teoría la encontramos en Montgomery: "As 26 the poem has it, it was during this feast that the Count was sent a large amount of food; he was being asked to do nothing less than join in the celebration of

${ }^{7}$ Así lo creía, sin embargo, Garci-Gómez, quien llegaría a afirmar que "El Conde de Barcelona, qué duda cabe, se portó como auténtico folon [sic] hasta el final, y lograría por el ayuno doblegar la voluntad de aquel ante quien había sucumbido por las armas” (Estudios, 127).

8 "Debemos admirar su magnanimidad [la del Cid] al perdonar la vida a los moros a los que derrota y, en especial, cuando permite a Ramón Berenguer que regrese, libre, a su corte, con dos de sus caballeros. Este último episodio es el único, a lo largo de todo el poema, en que el Cid se nos aparece cruelmente sarcástico con su enemigo, al obligarle a participar en el banquete en el que se celebra su propia derrota. El poeta parece haber ideado este episodio como uno de los pasajes cómicos de su obra, ya que a esto se prestaba la figura refinada del conde. El sarcasmo e ironía del Cid reflejan la idiosincrasia de los castellanos, especialmente la del pueblo, que no comprende las costumbres de otro país y que, además, es enemigo”.

9 "There may be further humiliation intended when the Count is invited to participate in the banquet held to celebrate his own defeat (rather than being offered food from it to eat in private), especially as the booty is being piled up nearby (vv. 1015-1016)".

10 [Para el v. 1019]: "The Count is being asked to take part in a banquet to celebrate his own defeat”.

11 West ("A Proposed Literary Context", 2) halló otro motivo que, sin embargo, resulta difícil de sostener a la vista de lo que reza el poema. Para el autor, "Montgomery believed that the Count refused food because he was being invited — and somewhat rudely - to celebrate his own defeat. This seems eminently sensible, for the Cid's treatment of his noble prisoner is not over-generous. The Count is not invited to join him at table, instead the food is placed before him while he is still under guard. The Cid's men are undoubtedly celebrating their victory and there is no sign of the Cid's magnanimity at this point". Sin embargo, el conde replica en cierto momento al Cid diciéndole "-Comede, don Rodrigo e pensedes de folgar, / que yo dexarm'é morir, que non quiero yantar.-” (vv. 1027-1028), por lo que catalán y castellano sí podrían estar compartiendo mesa. Por otro lado, no sabemos si las celebraciones por la victoria duraron tres días, pues nada dice el CMC al respecto, siendo por tanto una afirmación gratuita del autor que, además, poco aporta a su razonamiento.

Medievalia 49, 2017, pp. 21-61 
his own defeat" ("The Cid and the Count", 5). Sin embargo, una lectura atenta del texto descarta esta interpretación, pues cabría preguntarse por qué el Cid no celebra la victoria con sus hombres. El v. 1011 deja claro que el Cid "Prísolo al conde, pora su tienda lo levava", esto es, el Campeador no dejó al conde con el resto de prisioneros, sino que lo hizo llevar a su propia tienda, lo cual apunta más bien al trato que se dispensaría a un invitado y no a un cautivo. Al igual que, hoy en día, cualquiera intenta que sus invitados se sientan satisfechos y nada les falte, Rodrigo agasaja al conde en lo que parece un claro trato preferente, quizá incluso compartiendo con él su propia comida. ${ }^{12}$ Por otro lado, el comportamiento del Cid recuerda poderosamente a la costumbre musulmana por la que el vencedor ofrecía alimento a su prisionero, manifestando así su intención de respetarle la vida. Uno de los ejemplos más célebres es el protagonizado por el gran Saladino, quien, tras su victoria en Hattin, ofreció a su prisionero Guido de Lusignan una copa de agua helada. Tras saciar su sed, el entonces rey de Jerusalén pasó la copa a otro prisionero, Reinaldo de Châtillon, al que Saladino había jurado matar con sus propias manos. Al ver cómo Reinaldo bebía, Saladino hizo notar, en voz alta, que no era él quien había ofrecido el líquido elemento a este prisionero. Tras ello, sacó su espada y le golpeó con tal violencia que le separó el brazo derecho del cuerpo por el hombro para, a continuación, ordenar a sus lugartenientes que le diesen el golpe de gracia (Jacob, Procter, Riddle y $\mathrm{M}^{\mathrm{c} C o n e c h y, ~ H i s t o r y ~}$ of the Ottoman Empire, 202; Regan, Saladin, 129; Oldenbourg, Las cruzadas, 573; McGlynn, By Sword, 103). La reacción del conde resulta acorde con esta interpretación, pues adopta una postura que constituye una oposición frontal a la de su captor: si el Cid ofrece comida a don Remont para indicarle que va a respetar su vida, este último decide dejarse morir, herido en su orgullo tras su derrota ante quienes considera unos "malcalçados": ${ }^{13}$

\footnotetext{
${ }^{12}$ No estoy de acuerdo, por tanto, con la interpretación de Montgomery, para quien "He [el conde] is made captive, and when a victory feast is prepared for the Cid, he declines to take part: 'A Mio Çid don Rodrigo grant cozínal' adobavan; / el conde don Remont non ge lo preçia nada.' (vv. 1017-1018) Mindful of the count's arrogance, the poet disingenuously treats his refusal as an expression of disdain, 'a todos los sosañava' (v. 1020), but it is quite clear that a game is beginning in which the Cid holds all the trump cards, and that the count's stubbornness will only intensify his final humiliation" ("Rhetoric of Solidarity", 200).

${ }^{13}$ Resulta muy interesante la observación de Burgoyne, comparando el calzado del ejército franco en la contienda con este insulto de "malcalçado", por el que se logra "a comic allusion to, and parallelism with the battle" ("Si bien non comedes", 40). Si bien estoy de acuerdo con el paralelismo de la contienda, en cuanto que la verdadera batalla se producirá en torno a esa comida, considero apriorística la calificación de cómica.
}

Medievalia 49, 2017, pp. 21-61 
-Non combré un bocado por cuanto ha en toda España, antes perderé el cuerpo e dexaré el alma, pues que tales malcalçados me vencieron de batalla.-

(vv. 1021-1023)

Se equivoca West ("A Proposed Literary Context", 2) al afirmar que "The precise reason for the fast is not explicitly given", pues estas líneas señalan dicho motivo, esto es, su derrota ante unos "malcalçados", como bien observaron Moon ("Humor", 702), ${ }^{14}$ Corfis ("Count of Barcelona”, 173) ${ }^{15} \mathrm{y}$ Montaner (Cantar, 792 [1993: 492; 2007: 448]), ${ }^{16}$ un desprecio que ya había mostrado en los vv. 980-981: “Lo de antes e de agora todo.m’ lo pechará, / sabrá el salido a quién vino desondrar!”. Conviene hacer hincapié en que no es sólo el hecho de haber sido vencido lo que aflige a don Remont, sino el haber caído ante enemigos que él considera inferiores, lo cual hace todavía más ignominiosa la derrota. ${ }^{17} \mathrm{El}$ ayuno constituye, así, una reacción coherente con

14 “The Cid and his followers are still 'malcalçados' to the Count. The incongruity of this bombastic figure sputtering over his defeat is the basis of the humor here. But his dignity is destined to suffer even greater humiliation. After having refused the Cid's offer of food, even the added promise of liberty does not at first bring him to relent, but as his hunger whets his better judgment, he finally accepts".

15 "The Count resisted because he could not accept defeat by such 'malcalçados”".

${ }^{16}$ Para el eminente autor, se trata de "una muestra de despecho (vv. 1018, 1020, 1024 [sic, por 1023]) [... . Por ello, creo que tiene razón M. Pidal al achacar el desplante de don Remont al disgusto por una derrota que él considera humillante”.

${ }^{17}$ Creo que no anduvo acertado Garci-Gómez al señalar que "si la razón del ayuno hubiera sido la derrota en sí, el Conde no hubiera comido nunca” (Estudios, 127), pues a don Remont, más que la derrota en sí, le duele haberla sufrido ante quienes considera inferiores. En este sentido, no han sido pocos quienes han visto en este episodio una manifestación del choque entre el infanzón que gana prestigio por sus méritos personales y la alta nobleza que se acomoda en su rango (Oleza, "Análisis estructural",197; Beltrán, "Conflictos interiores", 240; West, "A Proposed Literary Context”, 2; England, "Cid's Use of Parody”, 103; Burgoyne, "Si bien non comedes", 40). Aunque diversas pruebas apoyan el origen magnaticio del personaje histórico (Torre Sevilla, Linajes nobiliarios y El Cid y otros señores, 131-164; Montaner y Escobar, Carmen Campidoctoris, 14-17), no parece suceder así con el poético, pues el Cid que muestra el CMC es un infanzón, según había reconocido hasta ahora la crítica de modo unánime. Lacarra ("Linaje" y "Rodrigo") ha defendido que ese alto rango del Campeador histórico se da también en el poema, en una lectura que "no sólo obliga a la retorsión semántica de un elevado número de versos del poema, sino que elimina uno de sus más obvios sustentos argumentales" (Montaner y Boix, Guerra, 229, n. 163), y que puse de nuevo en duda a partir de su análisis de los flyting o combates verbales ("Combates verbales”, 415-19). Esta discusión no afecta al episodio de don Remont, ya que el desprecio del conde al Cid no tiene por qué deberse a su clase social sino al mero hecho de ser un desterrado, como deja claro en los vv. 
la altanería del conde, ya que se siente deshonrado, al igual que lo hicieron otros personajes literarios, paralelos, que la crítica precedente no ha observado:

La dueña por est' fecho fue tan envergonzada que por tal que muriese non queriá comer nada, mas un ama vieja, que la hobo criada, fíçol' creyer la dueña que non era culpada.

(Libro de Apolonio, estrofa 8; ed. Alvar, II: 21)

Junto a este caso, ya señalé ("Batalla de Tévar") las fuertes semejanzas entre el episodio del conde de Barcelona en el CMC y la derrota en batalla y posterior muerte por inanición de Drapes en el libro VIII (\$ 36-37 y 44) de La guerra de las Galias, atribuido a Aulo Hircio, donde el desarrollo de la contienda es prácticamente igual ${ }^{18} \mathrm{y}$ donde se incluye cómo "Drappes, quem captum esse a Caninio docui, sive indignitate et dolore vinculorum sive timore gravioris supplicii paucis diebus cibo se abstinuit atque ita interiit" (Gai Iuli Caesaris, De Bello Gallico, 22, \$ 44) ["ya sea por indignación y sentimiento de las prisiones ó por temor de un castigo más severo, no quiso comer en unos días, y así murió." (Julio César, Comentarios, 251-256)]. En este caso, y si dicha identificación es correcta, el ayuno del conde no trataría de retratarlo

980-981: “iLo de antes e de agora todo-m’ lo pechará, / sabrá el salido a quién vino desondrar!”, estado en el que se halla independientemente de su condición de infanzón o magnate.

${ }^{18}$ En ese caso, las tropas romanas ocupan zonas elevadas, mientras que los bárbaros de Drapes están en la posición baja, quedando así en desventaja posicional. Esto serviría para destacar la victoria del Campeador, quien, en situación semejante a la de Drapes, acaba imponiéndose al ejército de don Remont. Burgoyne ("Si bien non comedes", 40) se equivoca al leer el pasaje, extrayendo de él una interpretación social insostenible debido a dicha lectura errónea: "The audience can also visualize the physical positioning of the men on the battlefield, which becomes an effective poetic representation of the power inversion that has taken place: the lowly Castilian infanzón, exiled from his land, has taken the higher ground (v. 992), while the more noble Count, with his superior numbers and social status, fights from below to reassert his authority. This spatial orientation of bodies in the scene sets the stage for the poet's comic humiliation of the Count", insistiendo en ella más tarde ("Si bien non comedes", 43). En el v. 992, recordémoslo, el Cid advierte a sus hombres de que "Ellos vienen cuesta yuso e todos traen calças", esto es "vienen cuesta abajo", por lo que se entiende que los catalanes ocupan zonas elevadas. Por supuesto, la desafortunada lectura del pasaje desarticula dicho planteamiento.

Medievalia 49, 2017, pp. 21-61 
como un personaje pueril y terco, ${ }^{19}$ sino que serviría para acercar los versos del CMC a su fuente latina.

Este sentimiento de deshonor que sufren Drapes y la hija del rey Antioco implica que la lectura tradicional derive a un razonamiento circular: si "el magnate desdeñoso se humilla, abandona sus resistencias, olvida su dignidad” (Oleza, "Análisis estructural”, 205), entonces acaba aceptando la comida que le ofrece un "malcalçado". En otras palabras: la consabida humillación sólo podría darse si el Cid lograse hacer comer al conde pese a que éste siguiese considerándolo un "malcalçado". Y no sólo esto: dejar marchar al conde humillado implicaría que éste, ya libre, seguiría pensando que el Cid era un "malcalçado". Ahora bien: García Ordóñez es humillado en las cortes de Toledo cuando insulta la barba del Cid, a lo que el Campeador replica recordándole lo sucedido en Cabra; Asur González despreciará al Cid al tildarlo de molinero y acabará herido de muerte en las lides finales; y, por supuesto, los infantes de Carrión sufrirán las consecuencias de la afrenta de Corpes y por despreciarlo a causa de su baja clase social. Así pues, ¿por qué debería el Cid dejar libre a quien le desprecia, cuando aquellos que lo hacen acaban recibiendo su castigo en el CMC? Todo apunta a que, si dejó marchar a don Remont, fue porque primero logró ganarse su respeto. Y eso sí casa con el espíritu del CMC, donde Rodrigo logra cambiar los corazones de quienes, en algún momento, han ido en su contra: los prestamistas Rachel y Vidas, que esperaban enriquecerse a costa del Cid, acabarán suplicando la devolución del dinero prestado; los moros de Alcocer, que acabarán despidiendo entre lágrimas al Campeador $y$, finalmente, el rey Alfonso, que cambiará su ira por amor hacia el héroe. En esa lista, probablemente, haya que incluir al conde, porque son aquellos que no aprenden a respetar al Cid quienes acaban siendo castigados y humillados en el poema, y no como el conde, marchando a lomos de palafrenes enjaezados. ${ }^{20}$

19 "The hunger strike seems pointless and infantile" (Montgomery, "The Cid and the Count", 2); "he renounces his stubborn plan and is thus humiliated" (West, "A Proposed Literary Context", 2); "his seemingly childish refusal to eat" (Corfis, "Count of Barcelona", 170).

${ }^{20}$ Creo, por ello, que Montgomery ("The Cid and the Count", 3) se equivoca al afirmar que "it is hard to imagine that the Cid felt a friendly concern about his prisoner's well-being, or that he wished to treat him as an honored guest, for the two men were by no means on friendly terms". Si no lo estaban al inicio del episodio, sin duda la situación ha cambiado mucho al final de la misma, y ello se debe al buen trato que Rodrigo dispensa al conde.

Medievalia 49, 2017, pp. 21-61 


\section{De cómo el Cid Se ganó EL RESPETO DE DON REMONT}

Si la batalla de Tévar se describe brevemente en el $C M C,{ }^{21}$ ello se debe a que la verdadera batalla iba a darse en torno a una mesa y no contra un ejército armado, sino contra la altanería del conde de Barcelona, en una contienda por dejar de ser considerado un "malcalçado". Para Navarrete, "si el deseo del juglar hubiera sido presentar a Rodrigo como un guerrero invencible el conde de Barcelona tenía que haber sido concebido como un adversario digno del héroe. No es así. El juglar del Mio Cid hace escarnio del conde de Barcelona” (“Ideología”, 238), sin advertir que la fácil victoria militar del Campeador remite a que la fuerza de don Remont no se sostiene sobre las mismas virtudes que las del Cid, esto es, sus capacidades guerreras, sino en su orgullo de conde, del mismo modo que la peligrosidad de los infantes de Carrión se alzaba sobre su desmedido egoísmo y orgullo (Hart, "Infantes de Carrión"). Por ello, que el conde se mantenga tres días en ayuno no significa que no haya podido resistir más, sino que esos son los días en que el Cid tarda en vencerle, tal es el orgullo del catalán, cuya resistencia contrasta con su rápida derrota en la batalla campal —así, la supuesta facilidad con que se rinde al hambre se convierte en un juicio subjetivo-.

Esa resistencia de varios días es incuestionable, sin que ello afecte a la teoría de la doble narración de Gornall, para quien el Cid no pide al conde que coma en dos ocasiones sino una, ${ }^{22}$ pues el CMC especifica que el Campeador y sus hombres insistieron durante tres días:

${ }^{21}$ En su afán por encontrar rasgos cómicos o humillantes en el episodio, algunos autores han creído ver elementos humorísticos que en ningún momento figuran en la narración, lo cual la hubiese extendido sensiblemente. Valgan unos pocos ejemplos donde se observan lo que podríamos llamar refundiciones de los hechos por parte de algunos críticos: Navarrete creía que la batalla se describía en "versos burlones en los que vemos a las huestes catalanas rodar por el suelo como peleles" ("Ideología", 238); Garci-Gómez también ofrece una versión de los hechos que difiere de la ofrecida por el poema: "Para ganar, cada uno de los del Cid habría de poner fuera de combate a tres de los del Conde. Para conseguirlo harían que estos se lanzaran al ataque cuesta abajo, precipitándose montados sobre sus sillas coceras. De esta manera, cuando los del Cid hirieran y derribaran a un caballo, los que seguían se tropezarían y atropellarían unos con otros, quedando impedidos entre cinchas y correajes" (Estudios, 119); Beltrán no queda a la zaga en creatividad al afirmar que "los francos saldrán despedidos haciendo caer a los que les sigan de una manera que nos hace pensar en las famosas fichas de dominó"("Conflictos interiores", 240).

${ }^{22}$ Para el autor, el Cid no ofrece la libertad al conde en dos ocasiones, sino sólo una, pues la alegría de don Remont es la de alguien que oye la propuesta por primera vez (Gornall, "How Many Times", 71), a partir de lo cual identifica ambas ofertas. Sin embargo, el CMC no refiere dos sino hasta cuatro invitaciones, si se incluyen las ocasiones en que el Cid reitera

Medievalia 49, 2017, pp. 21-61 
Fasta tercer día no.l' pueden acordar;

ellos partiendo estas ganancias grandes, no.l' pueden fazer comer un muesso de pan.

(vv. 1030-1032)

Pero, tras esos tres días,

—Dixo mio Cid: _Comed, conde, algo,

ca si non comedes, non veredes cristianos;

e si vós comiéredes don yo sea pagado,

a vós e a dos fijosdalgo

quitarvos he los cuerpos e darvos é de mano.-

Cuando esto oyó el conde ya s'iva alegrando:

—Si lo fiziéredes, Cid, lo que avedes fablado, tanto cuanto yo biva seré dent maravillado.-

(vv. 1033-1038)

“Cuando esto oyó el conde ya s’iva alegrando”, una alegría sobre la que el poeta insiste en el v. 1049, "Alegre es el conde e pidió agua a las manos". Resulta llamativo advertir que la crítica defensora de la presencia de una humillación en el episodio no ha dedicado una sola línea durante tantos años a explicar cómo podía el conde estar tan alegre si acababa de ser humillado, ${ }^{23}$ frente a Garci-Gómez (Estudios, 123), quien intuyó la importancia de estos versos al señalar que "la agresividad del folon [sic] se amansa; maravillado, comenzó a alegrarse".

En realidad, la comicidad del episodio se sostiene fundamentalmente gracias al v. 960, donde puede leerse que "El conde es muy follón”, y, con ello,

su ofrecimiento pese a que el conde ya ha aceptado (vv. 1039-1040) e incluso cuando ya está disfrutando de su comida (vv. 1054-1055), produciendo así un efecto de insistencia, como si Rodrigo quisiera asegurarse de que el conde seguirá comiendo, y que funciona perfectamente con la doble solicitud anterior que Gornall identifica como única. Así pues, todas ellas podrían leerse como independientes, transmitiendo esa sensación de insistencia y paciencia con que el Cid acaba venciendo la resistencia del catalán. Por otro lado, no se puede obviar la acertada observación de Molho: "no se ha advertido, por ejemplo, que las fórmulas a las que recurre el Cid en su doble invitación no son idénticas" ("Inversión y engaste", 199). Gornall no hace referencia alguna al estudio de Molho en su artículo.

${ }^{23} \mathrm{Y}$, si lo ha hecho, la lectura no ha sido todo lo fructífera que debiera. Así, Burgoyne señala que "Ramón happily gives up his protest" ("Si bien non comedes", 43), sin advertir que esa felicidad choca frontalmente contra la tesis de la supuesta humillación y comicidad que defiende a lo largo de todo su estudio. 
"the autor announced the appearance of a buffoon in his poem" (Montgomery, "The Cid and the Count", 1), de ahí que toda la aventura se haya leído habitualmente bajo un prisma de sorna hacia don Remont, ${ }^{24}$ sin advertir que la alegría del conde indica el momento en que descubre que ya no tiene razones para persistir en su actitud, que no se rinde al hambre, humillado, sino que abandona el ayuno porque él mismo decide hacerlo. ¿Por qué iba a ser ignominioso aceptar alimentarse, viéndose libre más tarde? Humillante sería aceptar comer a la mesa de un "malcalçado" y luego seguir siendo su prisionero, pues esto sí que implicaría que el conde no habría podido resistir el hambre. Pero esta ecuación se quiebra porque va a ser liberado y, con ello, el Cid también le rompe todos los esquemas, todos sus prejuicios al descubrir la nobleza de espíritu de quien, pese a ser un proscrito, se comporta con una generosidad digna de los grandes nobles, pues uno de los rasgos propios de todo gran señor medieval es, precisamente, su generosidad (Boix, "Aspectos del héroe", 18). ${ }^{25}$ De hecho, si, como señala Burgoyne ("Si bien non comedes", 41-42), los constantes insultos del conde al Cid y sus hombres como "malcalçados" son su manera de despreciarlos en comparación con las calzas que él y sus hombres usaron en batalla, es de notar que, a partir del momento en que se cita dicha alegría, don Remont jamás volverá a referirse a ellos con tan insolente apelativo, lo cual refuerza aún más la idea del cambio de actitud en el catalán.

Un reflejo de su nueva actitud se observa en palabras del propio Campeador, quien, justo tras el asombro manifestado por don Remont, señala:

-Pues comed, conde, e cuando fuéredes yantado, a vós e a otros dos darvos he de mano,

\footnotetext{
${ }^{24}$ Creo que se exceden Such y Hodgkinson al indicar para el v. 960 que "The poet is quick to let us know how we are to react to his portrait of a vain, blustering, and foppish individual, viewed with no small measure of Castilian intolerance towards an effete Catalan nobleman" (Poem of my Cid, 99).

${ }^{25}$ Para los vv. 1035-1035b, Such y Hodgkinson señalan cómo "the Cid again displays his exceptional generosity: he might have been expected to demand a large ransom for his illustrious prisoner and his two companions"(Poem of my Cid, 103). No estoy de acuerdo con Gornall, quien minimiza este hecho: "the inclusion of two of his knights could hardly, for so self-centred a personage, have amounted to a vital novelty" ("How Many Times", 71). Se trata de una afirmación apriorística, que ve en el conde a alguien orgulloso pero no observa su evolución desde su primera definición como "follón" a su alegría y respeto hacia el Cid. Además, si tal acción no fuese importante, ¿̇por qué iba el Cid a liberar a dos hombres más, venciendo así la resistencia de don Remont?
}

Medievalia 49, 2017, pp. 21-61 


\begin{abstract}
mas cuanto avedes perdido e yo gané en canpo, sabet, non vos daré a vós un dinero malo, ca huebos me lo he e pora estos mios vassallos que conmigo andan lazrados.

Prendiendo de vós e de otros irnos hemos pagando, abremos esta vida mientra ploguiere al Padre Santo, commo qui ira á de rey e de tierra es echado.-
\end{abstract}

(vv. 1039-1048)

Bien señala Garci-Gómez que "el Cid entra en un tono de lamentación confidencial, tratando de explicar al Conde lo duro de su situación" y que "el Conde de Barcelona pareció comprender; no le importaba que el Cid se que34 dara con todo el botín de guerra" (Estudios, 128). En efecto, aquí surge una nueva incoherencia con la supuesta humillación: ¿por qué debería el Cid dar explicaciones a don Remont para que comprenda por qué no le devuelve el botín? ¿Acaso da explicaciones a los moros tras una batalla? No, por supuesto es innecesario explicar la práctica habitual tras una victoria, y aún menos al enemigo vencido. Lo que aquí se aprecia, acorde al cambio que experimenta don Remont, es una nueva muestra de cordialidad tras hacer las paces. Por ello, el Cid casi parece disculparse por no devolverle el botín al que, más bien, es su invitado, explicándole que no le mueve el ansia de riquezas, sino la necesidad de mantener a sus hombres.

Otro punto donde la crítica ha creído ver tintes humorísticos ha sido la fórmula "comed, conde", ya utilizada anteriormente por Rodrigo, cuya cacofonía produciría un "alliterative wordplay", como lo llamó Giles ("Del día que fue conde", 122). Así, para Smith, el autor del poema "seems to me to invite listeners and readers to hear tones of cruel humor throughout this episode, and in particular to speculate that the Cid's words Comed, conde (1025) are a punning jingle of a cruel kind also, especially as they are repeated in 1033, 1039 , and 1054 , by the Cid, and in the narrative voice by the poet (comiendo va el conde, 1052)" ("Tone of Voice”, 11-18), mientras que, para Espósito, "the paranomasia created by the near homophony of comed, comde generates much of the scene's humor" "Lexical Patterning”, 47). ${ }^{26}$ Sin embargo, estas

\footnotetext{
${ }^{26}$ Miletich ofrece una lectura aún más enrevesada: "in the episode of the Count of Barcelona, the excessive emphasis on the verb 'comer' and its association with the term 'conde' build up comically to a climax in which the dominance of 'comer' in the first series is superseded by the noun 'conde' in the second, resulting in a mock-heroic juxtaposition which suggests that eating and the count are one and the same at this point in the narrative. This is aptly
} 
lecturas no se sostienen ante la identificación establecida por England ("Cid's Use of Parody", 102) entre la escena del CMC que centra el presente estudio y la ceremonia de investidura referida en la Gran Crónica de Alfonso XI por la que el rey otorga a Alvar Núñez el rango de conde. ${ }^{27}$ La estructura de dicha ceremonia es paralela a la conversación del Cid con don Remont, incluyendo además la misma fórmula, ${ }^{28}$ lo que obliga a descartar que dicha cacofonía o cualquier yuxtaposición fuesen concebidas bajo premisas cómicas, pues, estando históricamente documentada en una ceremonia real, resulta inviable pensar que su cacofonía tuviese un propósito humorístico, burlón, en tal contexto. Cosa distinta es que, como el propio England ("Cid's Use of Parody", 103) defiende, el diálogo de don Remont y el Cid sea una parodia de dicha ceremonia pero, en ese caso, estaríamos hablando del conjunto de la escena, y no sólo de la fórmula. Para Bautista,

el Cid no se burla sólo del conde orgulloso, sino que plantea una parodia de su misma identidad como conde, por la cual el héroe queda estructuralmente en la misma posición que el rey [...]. Por su parte, Berenguer se presta inicialmente a la broma diciéndole al Cid que coma él, con lo que el paralelismo con la ceremonia [de investidura de condes] toma tintes deliberadamente cómicos. Por si ello fuera poco, el conde acaba comparando la comida con el Cid a la que probó el día en que fue investido con la dignidad condal, explicitando la identificación entre las dos escenas: "Del día que fue conde non yanté tan de buen grado, / el sabor que dend é non será olbidado". La parodia muestra bien el tono anti-aristocrático del Cantar, que se burla no solo del conde, sino también de los rituales que le son propios, y de las señas de identidad de este tipo de aristocracia. Para ello, además, el poeta ha presentado al conde de Barcelona bajo la imagen de un conde castellano, transformando la realidad institucional del primero, y modificando también lo que en los primeros pasos de los textos cidianos puede considerarse un episodio con tintes anticatalanes en un motivo que parodia ya a la aristocracia cortesana, colocando en cierta medida a Berenguer como un ejemplo más de ella (“Comed, conde”, 71-72).

emphasized in the line 'por que el conde don Remont tan bien volvie las manos'" "'Repetition and aesthetic", 192).

${ }^{27}$ Giles ("Del día que fue conde", 124-125) identifica una ceremonia semejante para investir a un marqués, siguiendo a Diego de Valera.

${ }^{28}$ Para Bautista "La repetición de las palabras, 'Comed, conde', constitutivas del ritual [... evidencia que el poeta alude claramente a esta ceremonia" ("Comed, conde", 71). 
Comprensiblemente, el autor interpreta la réplica de don Remont al Campeador afirmando que "se presta inicialmente a la broma", única explicación lógica aunque forzada por la lectura habitual, además de incoherente, pues resulta obvio que, sintiéndose tan humillado, el conde no tendría ganas de bromear, y aún menos con el "malcalçado". Pero intuye con excepcional perspicacia que el Cid "queda estructuralmente en la misma posición que el rey", por lo que esta fórmula podría servir para caracterizar al personaje, mostrando su nobilísimo corazón, que le hará digno de la posición que ocupará en Valencia, donde acabará actuando como un rey tras la conquista de la ciudad (Boix, "Doble faceta”, 228-230; "Rodrigo Díaz”, 188-190; El Cantar, 64-67, 93, 105-107, 152-154, 156-158). No cabría, pues, una lectura paródica de la ceremonia identificada por England, del mismo modo que sería inapro36 piado ver en el v. 1025 (“-Comed, conde, d'este pan e beved d'este vino") una parodia de la eucaristía, de la Santa Cena o incluso de Cristo, extremo que iría abiertamente en contra del espíritu del $C M C{ }^{29}$

\footnotetext{
${ }^{29}$ Burgoyne lleva su interpretación al límite cuando afirma que "the poet also makes use of a parodic allusion to the Eucharist to create humor in the scene that can remind his audience that the Cid is the perfect prince $[\ldots]$. Imagining that the Cid and his family can be viewed as chosen people $[\ldots]$ and keeping in mind the comic feast also contains popular parodic elements that may travesty the liturgy of the Eucharist, it could be helpful to remember Paul's first letter to the Corinthians, as it addresses the judgment, even sickness and death, that will befall those who eat, but do not recognize the body of Christ $[. .$.$] . The biblical allusion can$ enrich the joke, since the Count did not acknowledge his superior, the true prince favored by God, and he is judged accordingly. As with the presumptuous guests in the parable of the wedding feast in the Gospel of Luke, the audience could have been reminded that 'everyone who exalts himself will be humbled, and whoever humbles himself will be exalted' (14.7-11). The Count is removed from his place of honor, and the Cid, who accepts his exile with humble loyalty, will be exalted by the end of his trials when he is offered Alfonso's seat (a gift from the Cid himself) in Toledo (vv. 3114-3116)" ("Si bien non comedes", 45-46), aunque parece no recordar que, en esas mismas cortes, el Cid se referirá a don Remont como "buen señor" (v. 3194). Reconoce también el autor que "one may feel that my conclusion is taking these jokes too far by turning the Cid into a parodic, threatening Christ-figure in the Tévar episode, but as Smith has argued, it is not imposible that the poet employed biblical and liturgical elements in his work that have been overlooked by scholars" ("Si bien non comedes", 46). En efecto, como demuestran los estudios sobre fuentes bíblicas en el CMC, así como la aguda percepción de Hoban ("Improperia"), el autor manejaba símbolos y elementos de la cultura religiosa cristiana, pero eso no implica la parodia de los mismos, rozando la blasfemia. El respeto que se muestra hacia los símbolos y la religión cristiana a lo largo del $C M C$ hace que esta lectura sea muy arriesgada, si no inviable, a lo que es necesario sumar las incoherencias con el propio poema, ya que ni el Cid, ni sus hombres ni su familia se mueven por un sentimiento mesiánico, como si del pueblo elegido se tratase. Por otro lado, la audiencia del Cid casi necesitaba ser experta en teología para comprender una comicidad que no justifica una supuesta
} 
A todo ello habría que sumar el "tono antinobiliario" del poema, que lleva a Bautista a ver otra parodia en los versos "Del día que fue conde non yanté tan de buen grado, / el sabor que dend é non será olbidado” (vv. 10621063), siguiendo así la estela de otros estudiosos tales como Montgomery ("The Cid and the Count", 7), quien, aparte de afirmar que se trata de palabras poco amables, ${ }^{30}$ remite al tópico sentido democrático del poema: "The poet's grudge against this class constitutes one aspect of the famous democratic sense of the poem, which is echoed so often in Spanish literature" ${ }^{31}$ El pro-

parodia de la eucaristía que, por irreverente, iría contra la imagen del Cid, pese a que pudiera servir para humillar a don Remont por no reconocer — según Burgoyne- al Cid como a un superior, si bien su alegría al aceptar el alimento indique lo contrario. Los malabarismos del autor para ofrecer una explicación plausible sirven, en fin, para observar cuán difícil resulta encajar la supuesta comicidad del episodio con el conjunto del poema, y cuán incoherente resulta con el mismo si se va desarrollando dicha lectura al extremo pues, en lugar de cohesionar el texto, en realidad diverge del mismo cada vez más.

${ }^{30} \mathrm{En}$ "The Cid and the Count", 6, afirma que "in the Count's abject request for permission to leave are found the unkindest words of all", citando los vv. 1060 y 1062-1063, a saber: “-Si vos ploguiere, mio Cid, / de ir somos guisados; [...] Del día que fue conde non yanté tan de buen grado, / El sabor que dend é non será olvidado.-". La pregunta es sencilla: ¿por qué no son amables? ¿Meramente porque le pide marchar? El autor no considera que esto es un episodio de un largo poema y hay que darle conclusión de algún modo, y que el Cid no puede pedir al conde que se marche, pues daría la sensación de que está echando a su invitado. Si se refiere a que esa falta de tacto se halla en los vv. 1062-1063, en breve señalaré su cercanía con los vv. 2063-2067, lo que pone en serias dudas tal aseveración. Lo que sí resulta evidente es la supresión del v. 1061 en su cita, aunque la razón es obvia: en su artículo, Montgomery no explica la presencia de los palafrenes ricamente enjaezados, uno de los elementos que ponen en serias dudas toda la supuesta humillación, por lo que evita cualquier mención a los mismos.

${ }^{31}$ En la misma línea se manifiestan Smith, para quien el Cid es "deliberately offensive and cruel to the captured Count because of his rank" ("Did the Cid", 525), y Rodríguez-Puértolas, según el cual, "Para lograr el rebajamiento social y moral de la nobleza, todo procedimiento es bueno en el poema, y en especial se acude a uno de los más degradantes y fáciles de captar por el público: la ironía y el humor. Ambos permean tanto el episodio del león contra los infantes como el del conde de Barcelona" ("Poema de Mio Cid", 32). El autor se reafirma en su idea poco después: "Esto poco tiene que ver con la épica, si nos atenemos a lo dicho por Bowra: 'En el estadio aristocrático de la poesía heroica, cualquier tipo de humor es mucho más infrecuente... imperceptible casi en el Beowulf y el Roland' [...]; si alguien es ridiculizado es el personaje de extracción humilde, no el noble, como en el caso particular del PMC. Resulta evidente que en el cantar, más importante que mantener un tono tradicional y estrictamente épico es el deseo de glorificar a Rodrigo, a lo castellano y a los de abajo por el medio que sea. Nos encontramos no sólo ante una intención ideológica muy concreta, sino también ante el primer brote de casticismo castellano intolerante, con un 'eco del 'consensus' general que implica poca simpatía hacia los marginales - judíos-y hacia los nobles de primera categoría' $[\ldots]$. Y todo ello enmarcado en un contexto más general del enfrentamiento del pueblo con

Medievalia 49, 2017, pp. 21-61 
blema radica en que el CMC no es un texto antinobiliario, pues Rodrigo Díaz no sólo emparienta primero con unos condes — los infantes de Carrión-, sino también con los reyes de España. El Cid quiere ganarse el respeto de las clases altas y dar un buen matrimonio a sus hijas: “Plega a Dios e a Santa María / que aún con mis manos case estas mis fijas” (vv. 282-282b), y así se observa en diversas ocasiones: logrará ganarse el favor del rey, quien acabará devolviéndole su estima y honrándolo, mientras que el respeto entre el Cid y los condes Enrique y Raimundo de Borgoña es mutuo (vv. 3036-3037, 3107 3111, 3496-3498). ${ }^{32}$ Así pues, es necesario buscar interpretaciones alternativas a esos versos "Del día que fue conde non yanté tan de buen grado, / el sabor que dend é non será olbidado", cuyo entusiasmo se ha visto como una exageración fruto del hambre, ${ }^{33}$ pese a que en el CMC se halla una escena semejante donde nadie ha visto humillaciones, burlas o ironías:

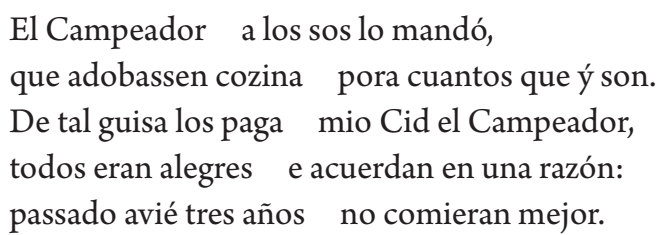

(vv. 2063-2067)

¡Tres años! Por supuesto, a nadie se le ocurriría pensar que estos nobles estén afirmando que, en sus casas o la corte del rey, no coman satisfactoriamente, sino que se trata de una muestra de admiración sincera, o incluso de

la nobleza, de pobres contra ricos, pues 'el motivo económico es tan dominante y patente que no se puede eliminar negándolo" (Rodríguez Puértolas, "Poema de Mio Cid”, 32). Toda esta argumentación resulta inconsistente al apreciar que el Cid del $C M C$ no lucha contra los ricos, sino más bien por salir de su pobreza, además de que el poema no es antinobiliario, como se verá a continuación.

${ }^{32}$ No puedo, por ello, compartir la opinión de Oleza, quien afirma que "el infanzón [el Cid] lucha contra la aristocracia de sangre por su ascenso social, al cual ésta se opone desde todos sus frentes (cortesano, feudal, etc.)" (“Análisis estructural”, 197), ni la de Rodríguez Puértolas: "Para lograr el rebajamiento social y moral de la nobleza, todo procedimiento es bueno en el poema, y en especial se acude a uno de los más degradantes y fáciles de captar por el público: la ironía y el humor. Ambos permean tanto el episodio del león contra los infantes como el del conde de Barcelona: 'se humoriza para hacer evidente la superioridad de unos personajes sobre otros" ("Poema de Mio Cid", 32).

33 "[El conde ] is forced to admit, 'del día que fue comde / non yanté tan de buen grado' $[\ldots]$. Even as renowned a person as the Count, with all his possessions and power, cannot provide a table as opulent as the Cid's" (Moon, "Humor", 702). 
gratitud y buenos modales hacia el anfitrión, alabando sus platos, costumbre elegante que se conserva hasta nuestros días.

No se trata del único gesto amable del conde hacia el Cid que señala su cambio de actitud, dejando de ser un "follón": otro ejemplo se encuentra en los versos donde se lava las manos, y donde no pocos críticos han visto el rastro de una cómica burla: ${ }^{34}$

Alegre es el conde e pidió agua a las manos,
e tiénengelo delant e diérongelo privado.
Con los cavalleros que el Cid le avié dados,
comiendo va el conde, ¡Dios, qué de buen grado!
Sobrél sedié el que en buen ora nasco:
—-Si bien non comedes, conde, don yo sea pagado,
aquí feremos la morada, no nos partiremos amos.-
Aquí dixo el conde: _ ¡De voluntad e de grado!-
Con estos dos cavalleros apriessa va yantando;
pagado es mio Cid, que lo está aguardando,
porque el conde don Remont tan bien bolvié las manos.

(vv. 1049-1059)

Me pregunto qué habría pasado si el conde, en lugar de lavarse, se hubiese abalanzado sobre la comida. Visto así, el pobre don Remont está a merced de ser zarandeado por la crítica, haga lo que haga: si olvida sus modales, podrá decirse que el conde se rebaja, se autohumilla, olvidando sus buenas maneras,

${ }^{34}$ Según Montgomery: "the poet takes him [al conde] over and proceeds, with great skill, to make a clown of him. His refined habits never leave him" ("The Cid and the Count", 6); para Corfis, "the contrast between the Cid's noble character and the Count's baseness, greed, and lack of humility is also apparent as the Count's decadent Frankish and aristocratic characteristics are developed through his pride and table manners" ("Count of Barcelona”, 170); para West, "The detail [pedir agua para las manos] reveals more than it states and suggests the scorn of the Castilians for such civilized pretensions" ("A Proposed Literary Context", 6). Giles ("Del día que fue conde", 125) observa cómo, en la investidura del marqués que halla en una epístola de Valera, el nuevo marqués sirve de aguamanos al monarca: en el caso del CMC se daría una inversión de papeles teniendo en cuenta que el Cid actúa como rey, pero esto conlleva dos problemas: por un lado, que esa parodia no tiene mucho sentido en un contexto donde, como se observa, el Campeador trata de ganarse el respeto del catalán; por otro, esa misma idea de parodia podría aplicarse a toda la escena por sus referencias eclesiásticas al nombrar al pan y al vino, lo cual supondría una lectura muy arriesgada (véase la nota 29 de este mismo artículo). Burgoyne remite a cómo "the social customs that are so important to Ramón are the source of ridicule for the Cid poet" ("Si bien non comedes", 42).

Medievalia 49, 2017, pp. 21-61 
dominado por el hambre; si mantiene los modales, entonces será un amanerado. Pero, si el conde "was going to have to make a spectacle of himself" (Montgomery, "The Cid and the Count", 5), su alegría resulta incoherente en tan humillante situación. Más bien, y esto sí da mayor cohesión al pasaje, creo que el conde no olvida cuáles han de ser sus modales ante un anfitrión que, en ese momento, ya se ha ganado todo su respeto, ${ }^{35}$ comportándose como lo haría en una corte ante la nobleza más alta, un respeto al que el Cid corresponderá, no hay que olvidarlo, regalándole unos caballos ricamente enjaezados (vv. 1064-1065), sobre los cuales volveré más tarde.

\section{LA SEGUNDA PARTE DEL EPISODIO SE ESTRUCTURA COMO EL ENGAÑO A RACHEL Y VIDAS}

Uno de los fragmentos más complejos de toda la aventura se halla al final de la misma, cuando el Cid ya se despide de don Remont:

—YYa vos ides, conde, a guisa de muy franco!
¡En grado vos lo tengo lo que me avedes dexado!
Si vos viniere emiente que quisiéredes vengallo,
si me viniéredes buscar, fallarme podredes,
o me dexaredes de lo vuestro o de lo mio levaredes algo._-

(vv. 1068-1072/73)

El lado humorístico que se ha querido ver en esta escena se apoya, esta vez, en que el lector sabe la verdad, esto es, que el conde no ha pagado nada, pese a el Cid le agradece "lo que me avedes dexado" del v. 1069, que, en realidad, no es sino el botín que ha ganado tras su triunfo (Montgomery, "The Cid and the Count", 6; Moon, "Humor", 702; Oleza, "Análisis estructural", 206; Gericke, "Humor irónico", 15). En ese sentido, recuerda poderosamente a la ironía dramática del episodio de las arcas de arena, donde tanto Rodrigo como Martín Antolínez y, por supuesto, el lector, son cómplices en la burla a Rachel y Vidas, pues todos ellos saben la verdad, mientras que los prestamistas la ignoran. Eso permite, por ejemplo, apreciar la ironía cuando, al escuchar la petición de una "piel bermeja, morisca e ondrada" que le hace Rachel (vv. 178-179), el Campeador responde:

\footnotetext{
${ }^{35} \mathrm{El}$ poeta "quiso dotar al noble de exquisitos modales, pues, a pesar del hambre, no se olvidó de lavarse las manos” (Garci-Gómez, Estudios, 128).
}

Medievalia 49, 2017, pp. 21-61 
—Plazme — dixo el Cid—, d'aquí sea mandada, si vos la aduxier d'allá, si non, contalda sobre las arcas.-

(vv. 180-181)

Pero, a diferencia de Rachel y Vidas, esta vez el conde también conoce las auténticas razones de su liberación. Y, por eso mismo, su respuesta está fuera de lugar:

-Folguedes ya, mio Cid, sodes en vuestro salvo;

pagado vos he por todo aqueste año,

de venirvos buscar sol non será pensado.-

(vv. 1074-1076)

como si le siguiera la broma (Garci-Gómez, Estudios, 128-130), aprovechando, además, el mismo recurso que el Cid utiliza para burlarse de él. Ciertamente, no creo que Rachel hubiese seguido también la broma al Cid si hubiese sabido el verdadero contenido de las arcas, y tampoco sería lógica tal reacción en alguien tan orgulloso como don Remont. ${ }^{36}$

Precisamente, el episodio de Rachel y Vidas puede ser útil a la hora de comprender el funcionamiento de la segunda mitad de esta aventura, ya que parece haberse estructurado utilizando el mismo esquema: ${ }^{37}$ se presenta el

${ }^{36}$ Para Oleza, "Es la ironía para la que el Cid se reconoce y se nombra, tras su victoria, superior a su enemigo. La frase final, incluso, puede ser tomada en doble sentido. No es sólo la afirmación de que uno de los dos ganará y arrebatará al otro lo suyo. Es tal vez la alusión a todo cuanto acaba de pasar, el reconocimiento de lo cual, en bien aprendida la lección, late en las palabras humorísticas, autohumorísticas mejor, del Conde" ("Análisis estructural”, 206). Ese "autohumorismo" carece de todo sentido, pues resulta incoherente con la supuesta humillación y el carácter orgulloso del conde.

${ }^{37}$ La semejanza entre estos personajes ya fue notada por Montgomery, aunque desde un enfoque distinto, siempre buscando la lectura humorística: "As in the two previous incidents [el engaño a Rachel y Vidas y la conquista de Alcocer], the Cid gains the advantage through knowledge of the particular weakness of the outsider. Knowledge and bravery are his weapons; knowledge, like wealth, is shared within his circle and denied to outsiders. They are synonymous with power. Lack of practical knowledge, equated with delusion, is weakness; it leads to failure [...]. The hero's superior knowledge, adroitly applied, brings each victim to grief, and affords the opportunity to laugh at his deluded state" ("Rhetoric of Solidarity", 200). Montgomery se refiere, en concreto, a cómo el Cid logrará convencer a don Remont de que coma. Sin embargo, la comparación con los prestamistas y Alcocer indica que ese "superior knowledge" sería su consciencia de que el orgulloso conde es también débil y no soportará su ayuno, lo cual haría innecesario cambio alguno en don Remont, que mantendría su mala opinión acerca del Cid, además de que los tres días de ayuno contrastan con su rápida derrota en el campo de batalla, según se ha indicado anteriormente.

Medievalia 49, 2017, pp. 21-61 
mismo número de actores, pero el cómplice del Campeador no es Martín Antolínez, sino don Remont, mientras que los personajes a quienes se engaña no son Rachel y Vidas, sino los dos hidalgos que marchan junto al conde y que desconocen por qué el Cid les ha concedido la libertad, pues no se hallaban presentes cuando el Cid la prometió a don Remont. ${ }^{38}$ El CMC describe con precisión el escenario: al partir, el conde marcha flanqueado por los dos hidalgos ("El conde don Remont entre los dos es entrado", v. 1066), y no tiene al Cid junto a él. Rodrigo es consciente de que los hidalgos oirán cualquier cosa que le diga y, con un nuevo acto de generosidad y elegancia, haciéndose todavía más acreedor del respeto del catalán, decide encubrir al conde, mintiendo sobre las verdaderas razones de su libertad. Para lograrlo, se dirige a don Remont con el famoso verso "ya vos ides, conde, a guisa de muy franco", tradicionalmente entendido como irónico, ${ }^{39}$ lectura ahora difícil de sostener

${ }^{38}$ Cuando el Cid ofrece al conde la liberación de esos dos hidalgos, estos no se hallan presentes, como indica el que se haga referencia a que los dos hidalgos se encuentran también en la mesa después de que el conde acepte comer a cambio de ser liberado, sin que sean nombrados nunca antes.

${ }^{39}$ Según Moon, "As a sort of good-natured parting thrust, the Cid somewhat ironically thanks the Count for increasing his wealth: 'Ya vos ides, comde - a guisa de muy franco, / 'en grado vos lo tengo - lo que me avedes dexado"”("Humor”, 702) para López Estrada, "la despedida de los dos está llena de la ironía que corre por debajo de las corteses frases que se cambian entre ambos; y esto llega al punto de que el Cid se permite incluso una traductio o juego de sentidos en la misma palabra: [cita el v. 1086] Sobre muy franco coinciden dos significados: 'muy catalán' en este sentido tópico al que me referí y 'libre por la generosidad del Cid', que los oyentes asociarían con regocijo" (Panorama crítico, 235); por su parte, Oleza piensa que "en el juego de palabras que combinan franco (catalán) con franco en sentido moral está presente la sonrisa burlona, irónica, del Cid” ("Análisis estructural”, 206); para Gericke "El Cid se divierte a expensas del adversario vencido en el episodio del conde Ramón Berenguer. $\mathrm{Al}$ darle la libertad prometida, lo despide con una broma: 'Hya vos ides, comde, a guisa de muy franco, / en grado vos lo tengo lo que me avedes dexado' (vv. 1068-69). Salta a la vista una de las notas irónicamente humorísticas, la de agradecerle el Cid al conde lo que le ha arrebatado. Otro aspecto del humor no es tan obvio porque depende de una ironía posibilitada por la polisemia del vocablo 'franco'. En un nivel significa 'libre', y es congruente con el significado del trozo porque el Cid ha puesto en libertad al conde. En otro nivel se refiere al origen étnico, ya que los catalanes eran francos por asociación con los franceses en la marca hispánica. Pero en un tercer nivel 'franco' puede significar 'dadivoso' o 'generoso'; el uso es irónico naturalmente, porque el conde mal de su grado le ha dejado al Cid en posesión de sus bienes, y ésta es la acepción que el juglar subraya en el verso siguiente donde la ironía de 'franco' es complementada por la de 'dexado', quizás con intención en la voz y ademán panorámico para señalar el botín"("Humor irónico”, 15); se excede hasta la violencia verbal Rutherford al interpretar las palabras del Cid como "there you go, free after being so generous as to make me these fine gifts, and behaving like any Frenchman: a pathetic effete arrogant coward perched 
tras el análisis realizado, pues las burlas quedarían fuera de lugar tras el cambio de actitud de don Remont. Teniendo en cuenta que, a los hidalgos, ese saludo no les sonaría en absoluto burlón, es fácil deducir que el Cid comienza la charla utilizando dobles sentidos para advertir al catalán el tono en que discurrirá la conversación, quien, a su vez, entenderá a su interlocutor de inmediato, como se observará a partir de ese instante. Tras agradecerle en voz alta "lo que me avedes dexado", atribuyendo que el mérito fuese del conde, que habría entregado una fuerte suma al Cid por el rescate de sus hombres y de sí mismo, don Remont replica usando hábilmente también palabras con doble sentido: la respuesta del conde "pagado vos he por todo aqueste año" (v. 1075) es un guiño que se hace eco de una petición anterior del Campeador:

Con los cavalleros que el Cid le avié dados, comiendo va el conde, ¡Dios, qué de buen grado!

Sobr' él sedié el que en buen ora nasco:

- Si bien non comedes, conde, don yo sea pagado, aquí feremos la morada, no nos partiremos amos.Aquí dixo el conde: _ ¡De voluntad e de grado!-

(vv. 1051-1056)

Rodrigo le pide que coma "don yo sea pagado" y, al marchar, don Remont le responde que ya le ha "pagado", lo cual puede entenderse como que le ha entregado suficiente dinero ${ }^{40} \mathrm{o}$ que deja al Cid satisfecho para todo el año.

Por otro lado, justo después de mencionar a los dos caballeros sentados a la mesa junto a su señor, el v. 1053 indica que el Cid se sienta "sobre" el conde, lo que no tiene por qué significar forzosamente "encima de", sino también “cerca, junto a”, como muy bien observó Smith:

It is possible, first, that the Cid is still trying to humble the Count by sitting at table with him, even though respect for the semi-royal personage should

on your pretty palfrey, happy to undergo any humiliation to save your precious skin, and more interested in your food than in your honour - all refinement and no substance, as opposed to us rough-and-ready yet practical and resourceful Castilians" ("The Comical and the Humorous", 766).

40 "El botín, del que el Conde no recuperará ni un dinero, equivale de hecho a un rescate, cuyo pago es la condición de libertad. El verso 1075: 'pagado vos he por todo aqueste año' manifiesta claramente que el catalán ha comprendido los designios del Cid, pues en él, bromeando, asimila sus pérdidas al servicio anual que un vasallo debe a su señor" (Molho, "Inversión y engaste", 200).

Medievalia 49, 2017, pp. 21-61 
demand that the Cid remain standing. But what is sobre here? To me it implies "sitting very close to, and leaning (offensively) towards:" the next two lines show that the Cid is rudely observing the Count at a very close quarters, counting his mouthfuls, for if the Count does not eat enough to satisfy the Cid's requirements, he will not be freed. Another possibility for sobre is stated by Horrent: he translates "Plus haut que lui était assis [le Cid]" and explains in a note that this is a "Manifestation concrète de la superiorité du Cid sur le comte de Barcelone" $[\ldots]$. The modern versions and translations are for the rest frankly disappointing: "se sienta a su lado" (Manent), "en frente se sienta el Cid" (López Estrada), "a su lado estaba sentado" (Ruiz Asencio), "junto a él se sentaba” (Marcos Marín), "beside him sat the Cid” (Hamilton and Parry), "sat beside him” (Merwin). Only Martínez Burgos of those consulted seems to have given some thought to the question: "Muy a su vera se estaba..." (“Tone of Voice”, 11-18).

En efecto, aunque al maestro le disgustasen algunas traducciones y versiones, intuyó con su proverbial perspicacia el sentido de cercanía que guarda "sobre", equivalente aquí a "junto a”, conservando así uno de los significados de "super" en latín (Montaner y Boix, Guerra, 58-59, nota 48). Al no relacionar estas palabras con las pronunciadas en la despedida, y comulgando con la lectura tradicional, vio en tal cercanía un gesto ofensivo. No consideró que, cuando el Cid insiste de nuevo animándole a comer, tiene que hablarle desde muy cerca, quizá al oído, evitando así que los nuevos comensales oigan el secreto precio de su libertad. Frente a estos susurros, al acompañar al conde y a sus caballeros hasta los límites del campamento, el Cid alza la voz para que los hidalgos escuchen una falsa versión de lo sucedido y crean que su señor ha logrado libertarlos, de ahí que el conde le siga el juego, salvaguardando así su honor. ${ }^{41}$ Narrativamente, además, esta lectura da sentido al hecho de que el

\footnotetext{
${ }^{41}$ No puedo compartir, pues, la lectura de Giles (“Del día que fue conde”, 125), quien entiende ese "sobr' él sedié" físicamente, sentando al Cid en una posición superior, como en un trono, pues esto llevaría a que los hidalgos pudieran escuchar la conversación entre el Cid y don Remont. Giles realiza esta lectura al identificar al Cid con el monarca en la ceremonia de investidura de un marqués descrita por Valera, a la que ya me referí en la nota 27. Sin embargo, esa comparación regia, muy aceptable teniendo en cuenta que el Cid llegará a ser casi un rey en Valencia, sería más bien figurada, sin que necesariamente Rodrigo tuviese que sentarse en una posición superior, por encima del conde. Por otra parte, y pese a que no comparto la idea de humillación que se desprende de sus palabras, Burgoyne ya intuyó un doble sentido: "The hero is figuratively 'on top of' the Count - 'sobr'él sedié- - just as he and his men were mounted on their horses during the battle: 'las armas avién presas e sedién sobre los caballos' (v. 1001). Once again, the Count is forcefully dismounted from his arrogant posture, and
} 
Cid quiera escoltar a la pequeña comitiva: no le mueve sólo la caballerosidad, sino el saber que esa sería la ocasión propicia para engañar a los hidalgos, encubriendo así al conde, que marcharía con su honor intacto.

Pero, además, queda un asunto pendiente por resolver entre el Cid y don Remont, y cuya solución permitirá la feliz conclusión de la aventura. La maestría del poeta queda aquí patente, pues demuestra su absoluto dominio del esquema narrativo, su minuciosidad a la hora de atar todos los cabos, y no olvida cómo el conde despreció al Rodrigo antes de la batalla:

Del conde don Remont venido l'es mensaje; mio Cid cuando lo oyó envió pora allá: —Digades al conde, non lo tenga a mal, de lo so non llevo nada, déxem’ ir en paz!Respuso el conde: _ — ¡Esto non será verdad! ¡Lo de antes e de agora todo.m’ lo pechará, sabrá el salido a quién vino desondrar!-

(vv. 975-981)

El Cid quiso evitar el enfrentamiento armado, mientras que el conde buscó el choque por despreciar al Cid no sólo como "malcalçado", sino también como militar. Por ello, una vez que el Cid se gana su respeto, añade una advertencia: "Si vos viniere emiente que quisiéredes vengallo, / si me viniéredes buscar, fallarme podredes, /o me dexaredes de lo vuestro o de lo mio levaredes algo._-” (vv. 1068-1072), que, como bien señala Oleza, "no es sólo la afirmación de que uno de los dos ganará y arrebatará al otro lo suyo. Es tal vez la alusión a todo cuanto acaba de pasar, el reconocimiento de lo cual, en bien aprendida la lección, late en las palabras humorísticas, autohumorísticas mejor, del Conde" ("Análisis estructural", 206). Por supuesto, no podía faltar la mención a la supuesta comicidad que sólo sirve para restar valor al pasaje: ${ }^{42}$ la advertencia del Cid da pie a que el conde pueda retractarse de aque-

again the Cid bears down on the Count physically and verbally, echoing the defeat in the pine forest" ("Si bien non comedes", 43).

42 Una prueba de cómo la lectura humorística puede arruinar magníficas apreciaciones se observa en el caso de Moon, quien, para explicar este momento, se enreda al tener que casar sus certeras apreciaciones con la manida comicidad: "This particular episode demonstrates perhaps better than any other the Cid's personal sense of humor. It is an artistic device which relieves the sobriety of his unfortunate position as an exile, and demonstrates the human qualities of this champion of superhuman exploits" ("Humor", 702-703). En efecto, la necesidad de mantener a sus hombres, que partieron de Burgos con grandes carencias económicas,

Medievalia 49, 2017, pp. 21-61 
llas palabras previas con las que despreció al Campeador, pues, si entonces provocó el combate, ahora preferiría evitarlo, refrendando su respeto a todo nivel hacia el castellano, pero también su temor, siempre utilizando los dobles sentidos del supuesto rescate - lo que la crítica ha entendido como "seguir la broma" o autohumorismo- ${ }^{43}$ para engañar a sus acompañantes, quienes podrán estar agradecidos a su buen señor — y no al Cid — al creer que ha pagado muy generosamente su libertad. ${ }^{44}$ Tal es el miedo que el recuerdo de la batalla despierta en el conde, que muy bien podría explicarse así que vuelva la cabeza, temiendo que el Cid rompa su palabra:

Aguijava el conde e pensava de andar, tornando va la cabeça e catándos' atrás, miedo iva aviendo que mio Cid se repintrá, lo que non ferié el caboso por cuanto en el mundo ha, una deslealtança, ca non la fizo alguandre.

Además de indicar hasta qué punto han cambiado las cosas, no creo que este gesto tenga nada de irónico y sí un tanto de siniestro, ya que el poeta hace girarse al conde temiendo un ataque del Cid por la espalda, movimiento que no resulta casual teniendo en cuenta que, históricamente, fue asesinado en 1082. Este guiño negativo hacia el conde no implica tampoco humillación, sino que, además de mostrar el temor que siente hacia el Cid, el poeta parece indicarnos por qué decidió poner como personaje a don Remont, el histórico

queda aquí resaltada, pero eso no es tanto un motivo cómico sino, más bien, un recurso que destaca la progresión del Cid, la misma que le hace merecedor de ese calificativo de "champion of superhuman exploits", amable exageración de Moon que olvida aquí la mesura del Campeador a lo largo de todo el poema.

${ }^{43}$ No puedo compartir, por tanto, la opinión de Garci-Gómez: "Reconciliados ya el Campeador y el Conde, el diálogo seguía entre ellos con tonos de humor jovial y amables indirectas; bromas entre camaradas que se divierten con tomaduras de pelo, por el estilo de las entrecruzadas por Martín Antolínez y Raquel y Vidas, por Raquel y Vidas y el mismo Cid” (Estudios, 128).

${ }^{44}$ Pese a que no ve un humor basado en la humillación, no puedo estar de acuerdo con la opinión de Garci-Gómez, para quien "El Cid, generoso en sus obras, se muestra bromista en sus palabras; da las gracias al Conde por las ganancias que le proporcionó la pelea, recordándole que si algún día se volvía a encontrar con fuerzas (ya que de vez en cuando le daban impulsos de venganza), podrían tornar al combate, a ver quién ganaba: [y cita los vv. 1068-1073] En respuesta, el Conde adopta un aire agridulce, como el del Cid; éste podía estar tranquilo por lo que a él tocaba" (Estudios, 130). 
Ramón Berenguer II Cabeza de Estopa, en lugar del verdadero contendiente en Tévar, Berenguer Ramón II, llamado el Fratricida por su implicación en el asesinato de su hermano. No, no es un error onomástico, como ha creído la crítica habitualmente, sino que por fin tenemos una respuesta que explica tal cambio: el poeta no quiso que su héroe honrase a un traidor, ni quiso inmortalizar a un magnicida en sus versos, de ahí que nunca aparezca en el poema. Al contrario, haciendo que se gire, nos lo muestra temeroso, precavido, lo cual sirve para engrandecer al Cid, quien jamás cometió traición ... no como otros. Y no estará de más recordar que Ramón Berenguer II Cabeza de Estopa fue el padre del "infante de Aragón" que se casa con Sol, o, lo que es lo mismo, de Berenguer Ramón III el Grande, que desposaría a su hija María. El poema adquiere, de este modo, una gran coherencia al remitir a sus versos finales, honrando al que fue yerno del Cid y a su estirpe, lo cual, a su vez, repercute en la grandeza del linaje del Campeador, pues “Oy los reyes d'España sos parientes son” (v. 3724).

\section{Muestras EVIDENTES DE RESPETO HACIA EL CONDE POR PARTE DEL CID: LOS PALAFRENES Y COLADA}

Una vez conseguido el respeto del conde, el Cid actuará en consecuencia recíprocamente, siempre mostrándose como aquello que don Remont ahora ve, esto es, como un gran señor. El primero de estos casos se halla en los vv. 1064-1065:

$$
\begin{aligned}
& \text { Danle tres palafrés muy bien ensellados } \\
& \text { e buenas vestiduras de pelliçones e de mantos. }
\end{aligned}
$$

Resulta llamativo que este regalo del Cid haya pasado desapercibido por la crítica, o, al menos, por quienes defendían la humillación del Cid hacia el conde, pues, en sus estudios referenciados en este artículo, ni Dámaso Alonso, ni Montgomery, ni West, Corfis, England, Giles, Gericke, Gornall, Molho o Moon, por citar algunos, hacen una sola referencia a estos ricos presentes, evitando así la difícil tarea de explicarlos a la luz de la supuesta comicidad del episodio. Son, por ello, especialmente loables los esfuerzos de quienes sí buscaron una explicación que permitiese conciliar las monturas con la humillación del conde. Así, para Oleza, "el juglar no se olvida de rodearlo de notas alusivas a su carácter inseparable del lujo y del boato cortesanos" ("Análisis estructural”, 206), aunque eso no explica la razón para ofrecer tales presentes a quien ha humillado, mientras que Burgoyne ofrece una respuesta más documentada y coherente: 
I have already argued that the defeated and the weak are associated with femininity, and the Barcelonans are especially impotent in this episode. As is well known, the palfrey is a docile horse used for travel by both men and women, but it is a mount often associated with ladies. Since the Count and his men did not know how to dress for war or ride their chargers in battle, gente palfreys and courtly garments are more appropriate for them ("Si bien non comedes", 45).

Burgoyne no sólo consigue una respuesta plausible y coherente con su lectura cómica del episodio, sino incluso con parte del poema. En efecto, el palafrén puede asociarse a las mujeres, como bien especifica el propio CMC:

Minaya a doña Ximina e a sus fijas que ha

e a las otras dueñas que las sirven delant,

el bueno de Minaya pensólas de adobar

de los mejores guarnimientos que en Burgos pudo fallar,

palafrés e mulas, que non parescan mal.

(vv. 1424-1428)

Resultaría incoherente regalar un caballo de batalla a aquel contra quien el Cid no quiso combatir, con quien acaba de hacer las paces y que, en la conversación final, deja claro que no le apetece en absoluto volver a enfrentarse a Rodrigo. Vista así la situación, regalar palafrenes para un viaje sería lo más adecuado además de coherente, ya que, como el propio Burgoyne señala, el palafrén es una montura de viaje tanto para hombres como para mujeres, de ahí que no sólo Jimena y sus hijas utilicen estos caballos, sino también el propio Cid en su comitiva al ir a las vistas, sin que ello implique que sea un afeminado:

¿quién vio por Castiella tanta mula preciada

e tanto palafré que bien anda,

cavallos gruessos e corredores sin falla,

tanto buen pendón meter en buenas astas,

escudos boclados con oro e con plata,

mantos e pielles e buenos cendales d'Andria?

(vv. 1966-1971)

Dentro en Valencia mio Cid el Campeador

non lo detarda, pora las vistas se adobó:

¡tanta gruessa mula e tanto palafré de sazón, 


$$
\begin{aligned}
& \text { tanta buena arma e tanto buen cavallo corredor, } \\
& \text { tanta buena capa e mantos e pelliçones! }
\end{aligned}
$$

Al final de las vistas, el Cid regalará muchas de estas monturas, sin que ello tampoco dé a entender que esté llamando "afeminados" o "amanerados" a quienes acepten tales dones:

$$
\begin{aligned}
& \text { Aquí.s metió en nuevas mio Cid el Campeador: } \\
& \text { tanta gruessa mula e tanto palafré de sazón, } \\
& \text { tantas buenas vestiduras que d'alfaya son, } \\
& \text { compeçó mio Cid a dar a quien quiere prender so don; } \\
& \text { cada uno lo que pide nadi no.l' dize de no. } \\
& \text { Mio Cid de los cavallos sessaenta dio en don. }
\end{aligned}
$$

(vv. 2113-2118)

Quiero destacar aquí que el poema no refiere que el Campeador regalase caballos diestros o corredores, esto es, caballos de combate, sino únicamente palafrenes. Al rey sí que le llegó a regalar monturas de ambos tipos:

D’estas vistas que oviemos, de mí tomedes algo:

tráyovos treinta palafrés, éstos bien adobados, e treinta cavallos corredores, éstos bien ensellados; tomad aquesto e beso vuestras manos.-

(vv. 2143-2146)

El Campeador, de nuevo, ofrecerá palafrenes entre otros muchos regalos a sus invitados a las bodas de sus hijas con los infantes de Carrión (v. 2254), y también los regalará a sus yernos junto con caballos de combate y sus dos famosas espadas (vv. 2570-2576). ${ }^{45}$

En todos estos casos, como se observa, los palafrenes son parte de los valiosos regalos con que el Cid obsequia a invitados y parientes, y aun al rey mismo, del mismo modo que despide al conde regalándole palafrenes junto con "buenas vestiduras de pelliçones e de mantos". Puede observarse aquí, una vez más, cómo el CMC vuelve una y otra vez sobre la generosidad propia de los grandes caudillos medievales, y especialmente de todo señor

${ }^{45}$ Cuando, en las cortes de Toledo, los infantes tengan que devolver la dote al Cid, el oro y la plata que se han gastado será entregado en especie, incluyendo valiosos palafrenes (vv. 3242-3245).

Medievalia 49, 2017, pp. 21-61 
de la guerra que quisiera mantener satisfecho a su comitatus (Boix, "Aspectos del héroe”, 18), ofreciendo versos muy similares a lo largo de todo el texto que deben ser interpretados bajo un mismo prisma, y aún más cuando ese enfoque coincide, precisamente, con la idea de que el Cid quiere que don Remont no le vea como un "malcalçado", sino como un gran señor. Así pues, los palafrenes no aparecen aquí como un medio sutil de burla o tal vez insulto, sino como presentes de gran valor que engrandecen la figura de un Cid que salió de Vivar sin nada, que se vio obligado a engañar a los prestamistas Rachel y Vidas, y cuya generosidad le hace acreedor de la estima de propios y extraños. ${ }^{46}$ Por ello, cuando el conde mira por fin a Rodrigo como a un gran señor, el héroe no va a defraudar al conde, mostrándose enormemente generoso, como ya lo ha sido al ofrecerle una rica comida y liberar a dos de 50 sus hombres.

Otro punto al que los defensores de la comicidad del episodio rehúsan enfrentarse figura en las cortes de Toledo, donde el Cid entrega la Colada a Martín Antolínez alabándola con estas palabras:

$$
\begin{aligned}
& \text { Martín Antolínez, mio vassallo de pro, } \\
& \text { prended a Colada, ganéla de buen señor, } \\
& \text { del conde Remont Verenguel, de Barcilona la mayor; } \\
& \text { por esso vos la dó, que la bien curiedes vós. }
\end{aligned}
$$

No ya los críticos que obviaron enfrentarse a los palafrenes, sino incluso los que dieron alguna explicación, rehúsan explicar por qué el Cid llama "buen señor" a don Remont. Sólo Espósito logra una rebuscada explicación, creyendo que, hacia el final de las cortes de Toledo y con la justicia ya hecha en favor del Cid,

The word comde is no longer shaded with the pre-trial cynicism of our poet. Through the process of the tribunal, not only does the Cid reestablish his honor, but in effect the whole feudal system is purged. [... The judicial process

\footnotetext{
${ }^{46}$ En ese sentido, son mucho más acertadas las reflexiones de Garci-Gómez, para quien "el magnánimo Cid, que le dijo [al conde] que no le devolvería nada en absoluto de las ganancias del botín, no escatimaría en arrear ricamente a sus huéspedes a la hora de partir: [y cita los vv. 1064-1065] Es más: en insuperable rasgo de cortesía, acompañaría al Conde y a sus dos hidalgos, personalmente, hasta el término del campamento, donde se despidió de ellos" (Estudios, 129).
} 
could be interpreted as a semantic purification of comde to vindicate the honor which should accompany the office. Even Ramon Berenguer's name is cleared in this episode by the Cid himself ("Lexical Patterning", 49).

Su afirmación se apoya en los vv. 3496-3498, donde Rodrigo abraza a los condes don Anrich y don Remond, sin notar que el Campeador llega a humillarse ante ellos ya en el v. 3036, invalidando así la existencia de un "pre-trial cynicism”. La humillación sufrida por el conde de Barcelona tampoco concuerda con estos versos, mientras que la lectura que aquí se defiende, donde el Cid obtiene el respeto de don Remont, no sólo evita incoherencias con estos versos sino que halla refrendo en ellos.

A MODO DE CONCLUSIÓN: UNA INTERPRETACIÓN COHERENTE

Tras la detenida lectura de la bibliografía existente hasta el momento, resulta difícil contener la admiración hacia quienes aceptaron el desafío que el CMC plantea con esta aventura y, con mayor o menor éxito, ofrecieron sus interpretaciones del episodio, alumbrando una producción metaliteraria que enriquece enormemente al poema. Gracias a sus estudios, sabemos de la existencia de ceremonias de investidura que debieron inspirar al poeta, el ambiente antifrancés de la época, o la situación decadente de la clase condal, entre otros muchos conocimientos que constituyen un caudal de datos excepcional, como pocos se hallan en relación con cualquier pasaje del CMC. Nuestro análisis aplaude y es deudor de tales estudios, sin los cuales no habría podido desarrollarse, y su propósito no es el de discutir muchos de los valiosos datos y descubrimientos surgidos a partir de su concienzudo análisis de la aventura de don Remont, sino que dichos hallazgos se interpreten bajo un manido enfoque humorístico que, a mi parecer, desluce tales aportaciones al forzar una interpretación de los mismos que, por incoherente con el poema, les impide brillar en todo su esplendor y mostrar no ya su sentido profundo, sino todo el valor de la labor encomiable desarrollada por quienes me precedieron.

En efecto, es muy posible que la audiencia del juglar conociese los pormenores de la investidura de un conde, pero la aventura de don Remont ha tratado de ser explicada como una reivindicación del héroe castellano frente a los héroes carolingios; Giles ("Del día que fue conde", 129-35), apoyándose en la identificación de England ("Cid's Use of Parody", 102), entiende que la escena sitúa al Cid como "rey" frente al conde, lo cual le lleva a ver 
reminiscencias de las pretensiones francas sobre la Marca Hispánica, pese a que el Cid jamás muestra en el poema intención alguna de conquistar tierra catalana; Corfis ("Count of Barcelona”, 170-171) encuentra en las Coutumes de Beauvaisis el gesto de aceptar la comida como símbolo de paz y rendición, y plantea que "The poet [...] may or may not have intended to portray the Campeador as ignorant of the French custom" ("Count of Barcelona", 174), una afirmación que podría hacerse extensiva a toda la audiencia del juglar, preguntándonos si conocerían las costumbres francesas, o habrían leído las Coutumes de Beauvaisis; si serían expertos en leyes o si conocerían los intereses francos sobre la Marca Hispánica; si habrían leído muchos poemas sobre héroes carolingios o, en caso de ser analfabetos, si los habrían oído cantar, deduciendo en ese caso que serían bilingües con gran dominio del francés.

52 La búsqueda constante de respuestas en fuentes ajenas al $C M C$, si bien loable por esfuerzo y resultados, delata la falta de explicaciones en el propio CMC acordes con la lectura cómica, lo cual revela la incoherencia de la misma con el poema, y lleva a la duda razonable sobre si la audiencia del juglar estaría capacitada para comprender un episodio que requería tales conocimientos.

Por otro lado, esas respuestas externas, ajenas a los versos del CMC, pueden justificar que se haya leído el episodio como un simpático entremés (Montgomery, "The Cid and the Count", 9-10; England, "Cid's Use of Parody", 103; Giles, "Del día que fue conde", 121; Burgoyne, "Si bien non comedes", 40, 45, 46), o "uno más en el progresivo avanzar victorioso del Cid hacia su meta" (Oleza, "Análisis estructural”, 198), cuya presencia resulta casi innecesaria para el texto, pues da la impresión de estar desconectado del resto del poema. La lectura humorística rompe la cohesión del episodio con el resto del poema hasta niveles de tal profundidad que afecta a otros elementos que, discurriendo por todo el poema, entroncan con este episodio. Así sucede con el uso de la comida en el poema, que coincide perfectamente con el episodio de don Remont:

la unidad de un grupo en el CMC o su relación de paz o conflicto con otra comunidad o individuo viene representada por su relación con la comida, esto es, el ayuno o la presencia de alimentos. Así, cuando el Cid marcha al destierro, su carencia de víveres se debe al conflicto con Alfonso VI. En situaciones de asedio, los agredidos sufren hambre. Por el contrario, cuando la relación es amistosa y no hay conflicto alguno, la comida está presente, incluso con gran abundancia, símbolo de la celebración de la unión de todos los miembros de una o varias comunidades sociales. Tal es el caso de los banquetes tras el perdón regio, o la comida que el moro Abengalvón ofrece a las gentes del Cid (Boix, "Comida", 40-41). 
El episodio del conde puede incluirse en esta lista: mientras don Remont se siente deshonrado, decide ayunar, mostrando su postura de enfrentamiento con respecto al Campeador. Pero, justo tras alegrarse por la oferta de libertad del Cid, cuando reconoce en Rodrigo a alguien de espíritu nobilísimo, acepta el alimento que le ofrece, en claro gesto conciliador hacia su anfitrión, y que vendría reforzado por la simbólica presencia del pan y el vino, que, como apuntó Garci-Gómez "compartir el pan y el vino es el signo de comunión cristiana” (Estudios, 122), lo cual es acorde con el uso de la comida en el CMC como signo de unidad, siendo más coherente al espíritu del poema que la supuesta parodia de la eucaristía que propuso Burgoyne.

Junto a esos episodios que revelan cómo funciona la comida en el CMC, y con los que la aventura de don Remont coincide al interpretarlo partiendo de una lectura sin humorismo, cabe también sumar este capítulo al engranaje de todos aquellos en los que el Cid acaba ganando no sólo botines o tierras, sino también la admiración y simpatía de los vencidos. El caso del rey Alfonso es el más claro, pero existe un episodio dentro del $C M C$ que funciona de manera muy cercana al que ocupa estas páginas, pese a que la crítica no lo haya advertido: se trata de la toma de Alcocer, donde la conquista guerrera precedió la de los corazones. Allí, tras hacerse con la plaza, el Cid explica a Minaya que

$$
\begin{aligned}
& \text { los moros e las moras vender non los podremos, } \\
& \text { que los descabecemos nada non ganaremos, } \\
& \text { cojámoslos de dentro, ca el señorío tenemos, } \\
& \text { posaremos en sus casas e d'ellos nos serviremos. }
\end{aligned}
$$

(vv. 620-622)

Si Rodrigo es consciente de que no gana nada decapitando a los moros, también sabe que de nada le servirá humillar al conde o dejarle morir, $y$, aunque en ninguno de los dos casos renuncia al botín obtenido, tampoco obtendrá rescate alguno por los prisioneros. Tal es su magnanimidad y nobleza que, al dejar Alcocer, los moros del lugar le brindarán esta emotiva despedida:

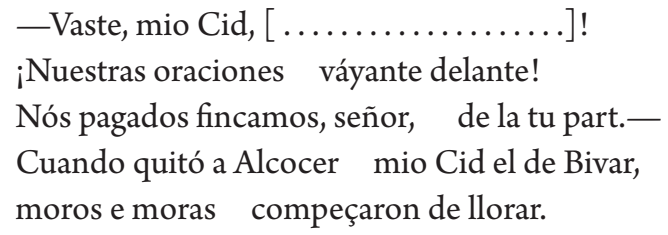

(vv. 853-856) 
Alcocer es un episodio antecedente del de don Remont, que, siguiendo la progresión ascendente del Cid a lo largo del destierro, constituye a su vez una mejora considerable de lo ganado en Alcocer, con un mayor botín y unos prisioneros de rango social muy superior al de los moros. Y, como se ha señalado a su vez, anticipa el perdón del rey, cuyo corazón será conquistado mediante constantes muestras de fidelidad y regalos como son, por ejemplo, los caballos. ${ }^{47}$ Los elementos comunes que la aventura de don Remont comparte con Alcocer o el perdón regio dota de coherencia a toda la narración del destierro y muestra cómo este capítulo constituye una pieza fundamental de todo el engranaje del poema como parte de esa progresión hacia el final del destierro, y como tal hay que entenderlo.

No sólo una lectura de la aventura de don Remont desde un prisma carente de humorismo concuerda con el poema mismo, sino incluso con las versiones que ofrecen las crónicas, y resuelve las dudas de Smith al respecto, quien se sorprendió de que diversos textos cronísticos no reflejasen el humor de la escena, presentando al Cid como un amable anfitrión, pese a que "One might expect that the chronicles, being close to the poem in time and hence it might be supposed in sentiment, would help our study" ("Tone of Voice", 12-13). Consideraba el mismo autor que

Although the chronicles preserve very full narrations of epic themes and much direct speech, and although they retain a good sense of drama, the subtleties of the Poema and those we may assume to have been present in the other poetic texts have been attenuated or ironed out in the official, slightly muted prose of the Alphonsine team [...]. The essential outline of the episode and much of its detail have been well preserved, but the subtleties have gone, and that sharp edge of cruel humor, insinuation, and provocation, has been blunted. Unquestionably, chronicle accounts were intended to be offered viva voce by a reader to a group of listeners (as well as to be studied by an individual in private), but the effect must have been rather muted and undramatic ("Tone of Voice", 13-16).

Pero tal vez eran las crónicas las acertadas y Smith erró al leerlas desde la consabida perspectiva humorística. El presente análisis, frente a dicha

\footnotetext{
${ }^{47}$ Pese a que sus argumentaciones difieren a menudo de las que aquí presento, Garci-Gómez intuyó la coherencia que este episodio debía de guardar con el resto del $C M C$ y, más en concreto, con el perdón real: "El Cid Campeador logró ablandar la furia del Conde de Barcelona por medio de su bondad y su generosidad, las mismas cualidades que en el Cantar de las Bodas ablandarían la ira del monarca” (Estudios, 131).
} 
interpretación, no necesita enfrentarse a la versión de las crónicas sino que halla respaldo en ellas, en cuanto que, si bien el tono del CMC y el de las crónicas no tiene por qué ser exactamente el mismo, sí que coinciden con nuestro estudio al no reflejar humor en este episodio. ${ }^{48}$ La Historia Roderici, más que probable fuente directa del episodio como han demostrado Montaner ("La batalla") y Luongo ("El discutido influjo"), sí incluye burlas en las cartas previas a la batalla, concretamente en la respuesta de Rodrigo, quien advierte que fue objeto de improperios por parte del propio conde y de algunos de sus hombres, respondiendo con burlas, desprecio e incluso señalando que sus fuerzas son más dignas de mujeres que de hombres (Historia Roderici, \$ 39). Sin embargo, tras hacerse con la victoria, la crónica muestra a un Cid duro, aunque piadoso también, que se niega a recibir al conde pero le ofrece alimento en gran cantidad y acaba liberándolo (Historia Roderici, $\$ 41)::^{49}$

48 "The Count of Barcelona episode is told at length in the chronicles, with much direct speech and many precise textual echoes of the poem, including some that are perhaps unexpected. Thus one or two of the possibly subtle points are retained, such as the hand-washing and the franco pun, but nothing is added by way of illustration which would help us to know how the chroniclers 'heard the tone' of the poem, and the detail sobr'el sedie is not present. Most notable is the way in which the (to me) cruelly sardonic Cid of the poem is turned into a beneficient host at the banquet. This is prepared por fazer plazer al conde don Remond (PCG 533.b.28; CVR cap. 19 the same). The Count as in the poem refuses to eat, but the Cid, on hearing this, fue a el, et como era omne mesurado, dixol assi... (PCG 533.b.37; CVR similar). What the Cid says in the chronicle is genuinely consoling: Conde, comet et beuet, ca esto en que uos sodes por uarones passa, et non uos dexedes morir por ello, ca aun podredes cobrar uuestra fazienda et endereçar esto (PCG 533.b.38; CVR similar); when the Cid promises liberty to the Count if he will eat, he does so con el grand duelo que ouo dell (PCG 534.a.4; CVR the same). On refusing to restore any of the booty to the Count (poem, 1041-45), the Cid has words of legalistic explanation credited to him in the prose: Pero tanto uos digo que de quanto uos auedes aqui perdudo, que uos non dare ende nada, ca non es fuero nin costumbre sinon si lo quiere fazer por su mesura aquel que lo gana (PCG 534.a.19; CVR the same). [...] At the Count's departure in the poem, the Cid escorts him fata cabo del albergada (1067), having provided three palfreys, dresses, and cloaks; in the chronicle, El Çid dioles estonces muy bien de uestir et espenssa fasta su tierra quanto les cumpliesse, et enviolos, et fue con ellos fasta la primera posada (PCG 534.a.36; CVR abbreviates, but the Cid fue con ellos fasta el primer albergue, cap. 19). What was a modest escorting of a few meters to the limits of the camp becomes a deferential journey of some hours, with albergada / albergue providing a sort of justification (but hardly an accidental one)" (Smith, “Tone of Voice”, 15-16).

49 "In this case, the tone of the Historia Roderici, which provided a substantial source for the poet at this point, may give helpful clues, particularly as the Historia is in plain Latin and in prose. Anyone who reads it can readily judge that in it the Cid is scornful and offensive. In the Cid's message to his ally Almuhazen of Saragossa, as the clash with the Count approaches, we find comitem uero et suorum bellatorum multitudinem omnino uilipendio et sperno (942.8).

Medievalia 49, 2017, pp. 21-61 
Comes autem Berengarius uidens et cognoscens se a Deo uerberatum et confusum et in manu Roderici captum, humilis misericordiam ei petens, ante Roderic $<$ um $>$ in suo temptorio sedentem peruenit eique indulgentiam multa prece expetiit. Rodericus autem eum benigne recipere noluit neque iuxta eum in temptorio suo sedere permisit sed foris extra temptoria eum custodiri a militibus suis iussit. Victualia quippe sibi largiter ibidem dari sollicite precepit, tandem uero liberum ad terram reuerti sibi concessit (ed. Falque, Gil y Maya, Historia Roderici, 76).

[El conde Berenguer, viendo y comprendiendo que por voluntad divina había sido herido, vencido y capturado por Rodrigo, pidiéndole misericordia humildemente, llegó a presencia de éste, que estaba sentado en su tienda y le pidió perdón con muchos ruegos. Rodrigo no quiso recibirle benignamente, ni le permitió sentarse junto a él en la tienda, sino que ordenó a sus caballeros que le custodiaran fuera. Ordenó solícitamente que le dieran allí abundantes vituallas y finalmente, le permitió volver libre a su patria] (Falque,"Traducción", 360).

Aquí no hay humor alguno, aunque Smith intente ver una humillación forzando el texto de la que adolece tras releerlo sin la distorsión de esa comicidad. Al contrario, se observa aquí un nuevo elemento que apoya la relación directa entre el CMC y la Historia, pues en ambos casos aparece un conde altanero antes de la contienda y humillado tras el desenlace del choque, de ahí que no sea necesario hacer más burlas sobre él, que parece haber aprendido la lección. Eso sí, el poeta aprovecharía esa humillación para alejarse del texto cronístico e introducir el episodio del ayuno, apoyándose en la fuente de $\mathrm{La}$ guerra de las Galias y la muerte por inanición de Drapes, lo cual le permitiría,

In the extensive exchange of letters between the Cid and the Count (reported only briefly by the poet, 975-82), the Count complains that Aliam quoque deteriorem iniuriam et derisionem nobis fecisti, que nostris uxoribus nos assimilasti (942.30), attacks the Cid's trust in auguries, and condemns him as aleuoso and a violator of churches. The Cid's reply includes the note that the Count is a windbag, Te autem superfluis iactando uerbis... (945.13), which surely provided the poet with the idea that the Count was muy folon. As to personal relations after the battle, Comes autem Berengarius,... humilis misericordiam ei petens, ante Roderici in suo tentorio sedentis peruenit, eique indulgentiam multa prece expetijt. Rodericus autem eum benigne recipere noluit, neque iuxta eum in tentorio suo sedere permisit, sed foris extra tentoria eum custodiri a militibus suis iussit (947.1). The matter could not be clearer, in these and many other details. The poet was not of course in any way obliged to follow the Historia slavishly, or at all, but in this instance he evidently found excellent dramatic material for his poetic scene, and not only adopted its tone but also elaborated upon it" (Smith, "Tone of Voice", 12).

Medievalia 49, 2017, pp. 21-61 
como se ha dicho ya, mostrar esta nueva y larga batalla, en torno a la comida, que también acabará ganando el Cid y donde se observará no ya una humillación sino algo más importante: que el Campeador logró ganarse el respeto de don Remont.

Creo adivinar que las burlas que aparecen en la Historia Roderici ejercieron una poderosa influencia a la hora de interpretar el episodio del CMC bajo una perspectiva cómica, lo cual permite comprender la reiterada lectura humorística sostenida por buena parte de la crítica, e iniciada fundamentalmente por Montgomery. Sin embargo, como se ha visto, eso no era posible sin la manipulación de la lectura, obviando el peso fundamental de la alegría del conde al cambiar su actitud hacia Rodrigo. Si esto fuese un juicio, podríamos argumentar que, quienes acusaron al conde de personaje risible, objeto de burla del Campeador, aplicaron su esfuerzo en ratificar una lectura aportando datos muy interesantes, pero a veces también muy rebuscados o con explicaciones enrevesadas para hacerlos encajar con la lectura humorística que, a la postre, sólo servía para convertir el episodio en un entremés. Frente a ello, el estudio que aquí termina se apoya en la navaja de Ockham por dar respuesta sencilla a todo el episodio al dotarlo de total coherencia con el resto del poema simplemente al suprimir la tan manida comicidad, ${ }^{50}$ enfoque que revela recursos estilísticos y estructuras que, junto con otros elementos y datos que ahora afloran, deberían haber sido considerados al interpretar un episodio que muestra a un Campeador que, como sucede en el resto de aventuras, es un personaje de alma noble, intachable, que no desprecia siquiera a quienes sí cometen el error de considerarlo inferior y sobre quienes se acaba siempre alzando victorioso, rindiéndolos con su corazón así como con las armas. ${ }^{51}$

\footnotetext{
${ }^{50}$ Pese a no coincidir en muchos planteamientos — comenzando por el hecho de que no creo que el ayuno sea una huelga de hambre-, Garci-Gómez llegó a conclusiones semejantes: "El episodio del Conde de Barcelona deberá ser interpretado como el pasaje de la niña de nuef años (40), como el de las dos archas (85), como los de las tomas de Casteion (435) y de Alcoçer (553); en función del engrandecimiento moral del héroe, como piezas que son de un mismo engranaje estructural” (Estudios, 117); volverá a señalar esta apreciación poco después: "El episodio del Conde no es, pues, un entremés extraño y chocante en la Gesta; su tema es el tema de la obra total: la justificación del Campeador, la exaltación de su valor y magnanimidad” (Estudios, 131).

${ }^{51}$ Quiero expresar mi sincero agradecimiento al doctor Alberto Montaner Frutos, por su revisión del texto original de este trabajo y sus diversas sugerencias. Mi gratitud, por supuesto, no implica su conformidad con cualquiera de las ideas u opiniones expresadas a lo largo del presente estudio, de las cuales soy total y único responsable.
}

Medievalia 49, 2017, pp. 21-61 


\section{BIBLIOGRAFÍA}

Alonso, DÁmaso, "Estilo y creación en el Poema del Cid", Escorial, 8, 1941, 333-372. Bautista, Francisco, “'Comed conde': las transformaciones de un ritual del Cantar de Mio Cid a Diego de Valera”, en Nelly Labère (ed.), Être à table au Moyen Âge, Madrid: Casa de Velázquez, 2010, 65-75 (Collection de la Casa de Velázquez, 115).

Beltrán, Luis, "Conflictos interiores y batallas campales en el 'Poema de Mio Cid'”, Hispania, 61:2, 1978, 235-244.

Boix Jovaní, Alfonso, "La doble faceta del Campeador en el Cantar de Mio Cid", Revista de Literatura Medieval, 17, 2005, 223-232.

Boix Jovaní, Alfonso, "Aspectos del héroe germánico y nórdico en el Cid”, Ínsula, 731, Noviembre 2007, 17-19.

Boix Jovaní, Alfonso, “Rodrigo Díaz, de señor de la guerra a señor de Valencia”, Olivar, 10, 2007, 185-192.

Boix Jovaní, Alfonso, "Combates verbales en el Cantar de Mio Cid", Bulletin of Spanish Studies, 85:4, 2008, 409-419.

Boix Jovaní, Alfonso, "La comida, la Regula Benedictina y el Cantar de Mio Cid", en Patrizia Botta (coord.), Rumbos del Hispanismo en el umbral del Cincuentenario de la AIH, Aviva Garribba (ed.), II. Medieval, Roma: Bagatto Libri, 2012, 35-41.

Boix Jovaní, Alfonso, El Cantar de Mio Cid: adscripción genérica y estructura tripartita, Vigo: Academia del Hispanismo, 2012.

Boix Jovaní, Alfonso, "La batalla de Tévar: de la Guerra de las Galias al Cantar de Mio Cid”, en Marta Haro (ed.), Literatura y Ficción: 'estorias', aventuras y poesía en la Edad Media, Valencia: Universitat de València, 2015, 133-145.

Burgoyne, Jonathan, “'Si bien non comedes, conde’: Food Rituals, Alimentary Imagery, and the Count of Barcelona's Comic Feast in the Cantar de mio Cid", eHumanista, 25, 2013, 31-50.

Cantar de Mio Cid, edición, estudio y notas de Alberto Montaner Frutos con un ensayo de Francisco Rico, Madrid: Real Academia Española-Barcelona: Galaxia Gutenberg, 2011 (primera edición en Barcelona: Crítica, 1993; reed. Barcelona: Galaxia Gutenberg-Círculo de Lectores, 2007).

Carmen Campidoctoris o poema latino del Campeador, estudio preliminar, traducción y comentario de Alberto Montaner y Ángel Escobar, Madrid: Sociedad Estatal España Nuevo Milenio, 2001.

Corfis, Ivy A., "The Count of Barcelona Episode and French Customary Law in the Poema de mío Cid”, La Corónica, 12:2, 1984, 169-177.

England, John, “'Comed, conde': the Cid's Use of Parody”, Medium Aevum, 63, 1994, 101-103. 
Espósito, Anthony P., "Comed, comde: Lexical Patterning as Thematic Reinforcement in the Poema de mio Cid", La Corónica, 15:1, 1985-1986, 46-51.

Falque, Emma, “Traducción de la Historia Roderici”, Boletín de la Institución Fernán González, CSIC, no 201, año LXII, segundo semestre de 1983, 339-375.

Falque, Emma-Gil, Juan-Maya, Antonio, Historia Roderici vel gesta Roderici Campidocti, Turnhout: Brepols, 1990 [Chronica Hispana saeculi XII. Pars I].

Gai Iuli Caesaris, De Bello Gallico. Commentarius Octavus, with a map and English notes by A. G. Peskett, Cambridge: Cambridge University Press, 1885.

Garci-Gómez, Miguel, "Mio Cid". Estudios de endocrítica, Barcelona: Planeta, 1975.

Gericke, Philip O., "El humor irónico en la representación del Cantar de Mio Cid", en Juan Villegas (ed.), Actas del XI Congreso de la Asociación Internacional de Hispanistas, California: Universidad de California, 1994, V, 11-18.

Giles, Ryan D., “'Del día que fue conde’: The Parodic Remaking of the Count of Barcelona in the Poema de mio Cid", La Corónica, 38:1, 2009, 121-138.

Gornall, John, "How Many Times was the Count of Barcelona Offered his Freedom? Double Narration in the Poema de Mio Cid", Medium Aevum, 56, 1987, 65-77.

Hart, Thomas R., “The Infantes de Carrión”, Bulletin of Hispanic Studies, XXXIII, 1956, 17-24 [reed. en Hart, Thomas R., Studies on the "Cantar de Mio Cid", introd. J. F. Burke, London: Queen Mary, University of London, 2006, 14-21 (PMHRS, 54)].

Hoban, Richard, The 'Improperia' and the 'Poema de Mio Cid', with a foreword by George Dingsdale and an Introduction by David Hook, London: King's College, 2000 [Papers in Progress, no 3].

Jacob, Samuel-Procter, Cl.-Riddle, J. E.-MㄷNechy, J., History of the Ottoman Empire including a survey of the Greek Empire and the Crusades, London-Glasgow: Richard Griffin \& Co., 1854.

Julio CÉsar, Los comentarios de la Guerra de las Galias con la continuación de Hircio, traducción corregida de don Manuel de Valbuena, Paris-Buenos Aires: Sociedad de Ediciones Louis-Michaud, 1920 [?].

Lacarra, Ma Eugenia / Eukene, "El linaje de Rodrigo Díaz", La Corónica, 33.2, 2005, 111-125.

Lacarra, Ma Eugenia / Eukene, "Rodrigo Díaz re-visitado”, en Armando López Castro, y Ma Luzdivina Cuesta Torre (eds.), Actas del XI Congreso Internacional de la Asociación Hispánica de Literatura Medieval, León: Universidad de León, 2007, I, 81-94.

Libro de Apolonio, ed. de Manuel Alvar, Madrid: Fundación Juan March-Castalia, 1976, 3 volúmenes.

López Estrada, Francisco, Panorama crítico sobre el Poema de Mio Cid, Madrid: Castalia, 1982.

Medievalia 49, 2017, pp. 21-61 
Luongo, Salvatore, "El discutido influjo de la Historia Roderici en el Cantar de mio Cid”, e-Spania,15, 2013. Disponible en e-spania.revues.org/22297.

McGlynn, SeAn, By Sword and Fire. Cruelty and Atrocity in Medieval Warfare, London: Phoenix, 2008.

Miletich, John S., "Repetition and Aesthetic Function in the Poema de mio Cid and South-Slavic Oral and Literary Epic", Bulletin of Hispanic Studies, LVIII, 1981, 189-196.

Molho, Maurice, "Inversión y engaste de inversión: notas sobre la estructura del Cantar de Mio Cid”, en Organizaciones textuales (textos hispánicos), Actas del III Simposio del Séminaire d'Etudes Littéraires de l'Université de Toulouse-Le Mirail. (Toulouse-Mayo de 1980), Toulouse: Université de Toulouse-Le Mirail; Madrid: Universidad Complutense-Uned, 1981, 193-208.

60 Montaner Frutos, Alberto, “La batalla de Tébar”, en César Hernández Alonso (coord.), Actas del congreso Internacional 'El Cid, poema e historia' (12-16 de julio, 1999), Burgos: Ayuntamiento, 1999, 353-382.

Montaner Frutos, Alberto y Alfonso Boix Jovaní, Guerra en Šarq Al'andalus: las batallas cidianas de Morella (1084) y Cuarte (1094), Zaragoza: Instituto de Estudios Islámicos y del Oriente Próximo, 2005.

Montgomery, Thomas, “The Cid and the Count of Barcelona”, Hispanic Review, 30:1, 1962, 1-11.

Montgomery, Thomas, “The Rhetoric of Solidarity in the Poema del Cid", Modern Language Notes, 102:2, 1987, 191-205.

Moon, Harold, "Humor in the 'Poema del Cid', Hispania, 46:4, 1963, 700-704.

Navarrete, Rosina D., "La ideología del "Poema de Mío Cid”", Hispania, 55:2, 1972, 234-240.

Oldenbourg, ZoÉ, Las cruzadas, Barcelona: Edhasa, 2003 (edición original: Les Croisades, Paris: Editions Gallimard, 1965).

OlezA, JuAn De, “Análisis estructural del humorismo en el Poema de Mio Cid”, Ligarzas, Valencia, IV, 1972, 193-234.

Regan, Geoffrey, Saladin and the Fall of Jerusalem, Beckenham, Kent-North Ryde, New South Wales-New York: Croom Helm, 1987.

Rodríguez Puértolas, Julio, “"Poema de Mio Cid”: nueva épica y nueva propaganda”, en Julio Rodríguez Puértolas, Literatura, historia, alienación, Barcelona: Labor, 1976, 21-43 [reeditado también, con ligeras modificaciones, en Alan Deyermond (ed.), Mio Cid Studies, London: Tamesis Books Ltd., 1977, 141$159]$.

Rutherford, John, “The Comical and the Humorous in the Poema de Mio Cid", Bulletin of Spanish Studies, 83:6, 2006, 739-769.

Sмith, Colin, “Did the Cid repay the Jews?”, Romania. 86, 1965, 520-538. 
Smith, Colin, "Tone of Voice in the Poema de mio Cid", Journal of Hispanic Philology, IX, 1984, 3-19.

The Poem of my Cid (Poema de Mio Cid), translated with an Introduction \& Commentary by Peter Such and John Hodgkinson, John, Warminster: Aris \& Phillips, 1987.

Torre Sevilla-Quiñones de León, Margarita C., Linajes nobiliarios de León y Castilla (siglos IX-XIII), Salamanca: Junta de Castilla y León, 1999.

Torre Sevilla-Quiñones de León, Margarita C., El Cid y otros señores de la guerra, León: Universidad de León, 2000.

Vidal Tibbits, Mercedes, "El Cid, hombre heroico y Beowulf, héroe sobrehumano”, en Antonio Torres-Alcalá et al. (eds.), Josep Maria Solà-Solé: Homage, homenaje, homenatge, Barcelona: Puvill Libros, 1984, I, 267-273.

West, Geoffrey, "A Proposed Literary Context for the Count of Barcelona Episode of the Cantar de Mio Cid”, Bulletin of Hispanic Studies, 58, 1981, 1-12. 
